\title{
Discovery and Synthesis of Heterocyclic Carboxamide Derivatives as Potent Anti-norovirus Agents
}

\author{
Mai Ohba, ${ }^{a, b}$ Tomoichiro Oka, ${ }^{c}$ Takayuki Ando ${ }^{a, b}$ Saori Arahata, ${ }^{d}$ Asaka Ikegaya, ${ }^{d}$ \\ Hirotaka Takagi, ${ }^{e}$ Naohisa Ogo, ${ }^{a, b}$ Kazuhiro Owada, ${ }^{b}$ Fumihiko Kawamori, ${ }^{d}$ Qiuhong Wang, ${ }^{f}$ \\ Linda J. Saif, ${ }^{f}$ and Akira Asai*,a \\ ${ }^{a}$ Center for Drug Discovery, Graduate School of Pharmaceutical Sciences, University of Shizuoka; 52-1 Yada, \\ Suruga-ku, Shizuoka 422-8526, Japan: ${ }^{b}$ Department of Pharmaceutical and Food Science, Shizuoka Institute of \\ Environment and Hygiene; 4-27-2 Kitaando, Aoi-ku, Shizuoka 420-8637, Japan: ' Department of Virology II, \\ National Institute of Infectious Diseases; 4-7-1 Gakuen, Musashimurayama, Tokyo 208-0011, Japan: ${ }^{d}$ Department \\ of Microbiology, Shizuoka Institute of Environment and Hygiene; 4-27-2 Kitaando, Aoi-ku, Shizuoka 420-8637, \\ Japan: ${ }^{e}$ Division of Biological Safety Control and Research, National Institute of Infectious Diseases; 4-7-1 Gakuen, \\ Musashimurayama, Tokyo 208-0011, Japan: and ${ }^{f}$ Food Animal Health Research Program, Ohio Agricultural \\ Research and Development Center, Department of Veterinary Preventive Medicine, College of Veterinary Medicine, \\ The Ohio State University; 1680 Madison Ave., Wooster, OH 44691, U.S.A. \\ Received January 1, 2016; accepted February 7, 2016
}

There is an urgent need for structurally novel anti-norovirus agents. In this study, we describe the synthesis, anti-norovirus activity, and structure-activity relationship (SAR) of a series of heterocyclic carboxamide derivatives. Heterocyclic carboxamide $1\left(50 \%\right.$ effective concentration $\left.\left(\mathrm{EC}_{50}\right)=37 \mu \mathrm{M}\right)$ was identified by our screening campaign using the cytopathic effect reduction assay. Initial SAR studies suggested the importance of halogen substituents on the heterocyclic scaffold and identified 3,5-di-boromo-thiophene derivative $2 \mathrm{j}\left(\mathrm{EC}_{50}=24 \mu \mathrm{M}\right)$ and 4,6-di-fluoro-benzothiazole derivative $3 \mathrm{j}\left(\mathrm{EC}_{50}=5.6 \mu \mathrm{M}\right)$ as more potent inhibitors than 1. Moreover, their hybrid compound, 3,5-di-bromo-thiophen-4,6-di-fluoro-benzothiazole $4 \mathrm{~b}$, showed the most potent anti-norovirus activity with a $\mathrm{EC}_{50}$ value of $0.53 \mu \mathrm{M}$ (70-fold more potent than 1). Further investigation suggested that $\mathbf{4 b}$ might inhibit intracellular viral replication or the late stage of viral infection.

Key words norovirus; heterocyclic carboxamide; antiviral activity; murine norovirus

Human norovirus causes acute nonbacterial gastroenteritis. Although the gastroenteritis symptoms are generally self-limiting, the elderly, infants, and immunocompromised individuals have a higher risk of mortality. Moreover, norovirus has a low infectious dose and spreads very easily from infected persons, contaminated food, water, or a contaminated environment. ${ }^{1)}$

Noroviruses are single-stranded, positive-sense RNA viruses that belong to the family Caliciviridae and genus Norovirus, and species Norwalk virus. The norovirus genome contains three open reading frames (ORFs): ORF1, ORF2, and ORF3. ORF1 encodes six or seven nonstructural proteins, including RNA-dependent RNA polymerase (RdRp) and 3C-like cysteine protease (3CLpro), responsible for viral replication. ORF2 and ORF3 encode the major and minor structural proteins, respectively. ${ }^{1)}$

Establishment of an efficient cell culture system for human norovirus is still challenging. ${ }^{2,3)}$ However, murine norovirus (MNV) can replicate efficiently in the murine macrophage cell line RAW264.7. MNV belongs to the genus Norovirus and shares common biological and molecular properties with human norovirus. ${ }^{4,5}$ Therefore, it is frequently used for identifying antiviral compounds based on the cell culture assay. ${ }^{6-12)}$

Several anti-norovirus agents have been reported that target viral attachment/entry, viral protein translation, or viral replication. ${ }^{7,8)}$ The RdRp inhibitor used as an anti-hepatitis $\mathrm{C}$ virus agent $2^{\prime}$ - $C$-methylcytidine $\left(2^{\prime}-\mathrm{CMC}\right)^{9,10)}$ and anti-influenza agent favipiravir ${ }^{11)}$ also have anti-MNV activity, and the broad spectrum 3CLpro inhibitor, dipeptidyl inhibitor GC376 also inhibits MNV protease activity in vitro. ${ }^{12)}$ Currently, there are no vaccines or drugs for clinical use, and there is an urgent need for new anti-norovirus compounds.

We describe here the discovery and synthesis of anti-norovirus thienyl benzothiazolyl carboxamide compounds bearing multiple halogen substituents, and discuss their structure-activity relationships (SARs) and biological activity.

\section{Results}

Screening and Discovery of Anti-norovirus Compounds More than 2000 compounds, which were selected from our in-house library, were screened with a qualitative antiviral activity assay. Each compound was mixed with MNV and the mixture was exposed to RAW264.7 cells. We used RdRp inhibitor $2^{\prime}$-CMC as a positive control and tested if it showed anti-MNV activity. We found that heterocyclic carboxamide derivative $\mathbf{1}$ had anti-norovirus activity. Compound $\mathbf{1}$ consisted of a 5-bromo-thiophene ring and 6-fluoro-benzothiazole ring linked by a central amide bond (Fig. 1). However, compounds 1a and $\mathbf{b}$, which had a phenyl ring instead of 5-bromothiophene ring, and 1c, which had an ethylene linker between the 5-bromo-thiophene ring and the amide bond, did not show antiviral activity. Therefore, we identified the thiophene-benzothiazole carboxamide as a key core structure and developed analogs of 1 to find a more potent agent.

Chemistry We focused on the halogen substituents on both the thiophene and benzothiazole rings in $\mathbf{1}$, and synthesized various halogenated analogs and other related derivatives (Chart 1). The coupling reagent 1-ethyl-3-(3- 
<smiles>O=C(Nc1nc2ccc(F)cc2s1)c1ccc(Br)s1</smiles>

1<smiles>[R]Oc1ccc(C(=O)Nc2nc3ccc(F)cc3s2)cc1O[R20]</smiles>

1a: $R_{1}=R_{2}=A c$

1b: $\mathrm{R}_{1}, \mathrm{R}_{2}=-\mathrm{CH}_{2}-$<smiles>O=C(CCC(=O)c1ccc(Br)s1)Nc1nc2ccc(F)cc2s1</smiles>

$1 \mathrm{c}$

Fig. 1. Structures of Hit Compound $\mathbf{1}$ and Inactive Analogs 1a-c<smiles>[R]C(=O)O</smiles><smiles>[R]C(=O)Nc1nc2ccc([R4])cc2s1</smiles>

$\mathrm{R}_{3}$ : Tables 1, 3. $\mathrm{R}_{4}$ : Tables 2, 3 .

Chart 1. Synthesis of Heterocyclic Carboxamide Derivatives

Table 1. Antiviral Activity and Cytotoxicity of 6-Fluoro-benzothiazole Analogs

\begin{tabular}{|c|c|c|c|c|}
\hline Compound & $\mathrm{R}$ & Substituent & $\mathrm{EC}_{50}(\mu \mathrm{M})^{a)}$ & $\mathrm{CC}_{50}(\mu \mathrm{M})^{b)}$ \\
\hline $2^{\prime}-\mathrm{CMC}$ & & & 56 & 12 \\
\hline 1 & & $5-\mathrm{Br}$ & 37 & $>100$ \\
\hline $2 a$ & & None & $>100$ & $>100$ \\
\hline $2 b$ & & $5-\mathrm{Cl}$ & 30 & $>100$ \\
\hline $2 c$ & & $5-\mathrm{F}$ & $>100$ & 1.9 \\
\hline $2 d$ & & $5-t-\mathrm{Bu}$ & $>100$ & $>100$ \\
\hline $2 e$ & & $4-\mathrm{Cl}$ & $>100$ & 52 \\
\hline $2 f$ & & $4-\mathrm{Br}$ & $>100$ & $>100$ \\
\hline $2 \mathrm{~g}$ & & $3-\mathrm{F}$ & $>100$ & $>100$ \\
\hline $2 \mathrm{~h}$ & & $3-\mathrm{Cl}$ & $>100$ & 65 \\
\hline $2 \mathrm{i}$ & & $3-\mathrm{Br}$ & $>100$ & 77 \\
\hline $2 \mathrm{j}$ & & $3,5-\mathrm{Br}$ & 24 & 7.9 \\
\hline $2 \mathrm{k}$ & & $3,5-\mathrm{Cl}$ & 6.6 & $>100$ \\
\hline 21 & & $4,5-\mathrm{Br}$ & $>100$ & $>100$ \\
\hline $2 \mathrm{~m}$ & & $4,5-\mathrm{Cl}$ & 24 & 22 \\
\hline $2 n$ & & $3,4,5-\mathrm{Cl}$ & 89 & $>100$ \\
\hline 20 & & None & $>100$ & $>100$ \\
\hline $2 p$ & & $5-\mathrm{Cl}$ & $>100$ & 74 \\
\hline $2 q$ & & $5-\mathrm{Br}$ & $>100$ & $>100$ \\
\hline $2 r$ & & None & $>100$ & 15 \\
\hline $2 \mathrm{~s}$ & & None & 65 & $>100$ \\
\hline $2 t$ & & $2-\mathrm{Br}$ & $>100$ & $>100$ \\
\hline $2 u$ & & $4-\mathrm{Br}$ & $>100$ & $>100$ \\
\hline $2 v$ & & $5-\mathrm{Br}$ & $>100$ & $>100$ \\
\hline $2 w$ & & $2,5-\mathrm{Br}$ & $>100$ & $>100$ \\
\hline
\end{tabular}

a) $\mathrm{EC}_{50}$ was evaluated by the CPE reduction assay. $280 \mathrm{TCID}_{50} / 50 \mu \mathrm{L}$ of MNV and a dilution series of each compound were incubated for 30 min. The mixture was exposed to RAW264.7 cells for $1 \mathrm{~h}$ (in duplicate). b) Cytotoxicity was evaluated by the WST-8 assay. RAW264.7 cells were treated with dilution series of each compound (in triplicate) for $72 \mathrm{~h}$.

dimethylaminopropyl)-carbodiimide hydrochloride $(\mathrm{EDC} \cdot \mathrm{HCl})$ and catalyst 4-dimethylaminopyridine (DMAP) were used to form the amide bond linking the heterocycles.

SAR The anti-norovirus activities of the analogs were evaluated by MNV-induced cytopathic effect (CPE) reduction assay. The $50 \%$ effective concentration $\left(\mathrm{EC}_{50}\right)$ and $50 \%$ cytotoxic concentration $\left(\mathrm{CC}_{50}\right)$ of the analogs are summarized in Tables 1-3. 
Table 2. Antiviral Activity and Cytotoxicity of 5-Bromo-thiophene Analogs

\begin{tabular}{|c|c|c|c|c|c|c|c|}
\hline \multicolumn{8}{|c|}{ 3a-x } \\
\hline Compound & $\mathrm{R}_{4}$ & $\mathrm{EC}_{50}(\mu \mathrm{M})^{a)}$ & $\mathrm{CC}_{50}(\mu \mathrm{M})^{b)}$ & Compound & $\mathrm{R}_{4}$ & $\mathrm{EC}_{50}(\mu \mathrm{M})^{a)}$ & $\mathrm{CC}_{50}(\mu \mathrm{M})^{b}$ \\
\hline $3 a$ & None & $>100$ & $>100$ & $3 m$ & $5,6-\mathrm{F}$ & $>100$ & 25 \\
\hline $3 b$ & $6-\mathrm{Cl}$ & 56 & $>100$ & $3 n$ & 6-Me & $>100$ & $>100$ \\
\hline $3 c$ & $6-\mathrm{Br}$ & $>100$ & $>100$ & 30 & 4-Me & $>100$ & $>100$ \\
\hline $3 d$ & $5-\mathrm{F}$ & $>100$ & $>100$ & $3 p$ & $5,6-\mathrm{Me}$ & $>100$ & $>100$ \\
\hline $3 e$ & $5-\mathrm{Cl}$ & $>100$ & $>100$ & $3 q$ & 6-OMe & $>100$ & $>100$ \\
\hline $3 f$ & $5-\mathrm{Br}$ & $>100$ & $>100$ & $3 r$ & 4-OMe & $>100$ & $>100$ \\
\hline $3 g$ & $4-\mathrm{F}$ & $>100$ & 5.1 & $3 s$ & 6-OEt & $>100$ & $>100$ \\
\hline $3 \mathrm{~h}$ & $4-\mathrm{Cl}$ & $>100$ & $>100$ & $3 t$ & $6-\mathrm{NO}_{2}$ & $>100$ & 17 \\
\hline $3 \mathbf{i}$ & $4-\mathrm{Br}$ & $>100$ & $>100$ & $3 u$ & $6-\mathrm{CF}_{3}$ & $>100$ & 11 \\
\hline $3 \mathbf{j}$ & $4,6-\mathrm{F}$ & 5.6 & $>100$ & $3 v$ & $6-\mathrm{OCF}_{3}$ & $>100$ & 22 \\
\hline $3 k$ & $4,6-\mathrm{Cl}$ & $>100$ & $>100$ & $3 w$ & 6- $\mathrm{CO}_{2} \mathrm{Et}$ & $>100$ & $>100$ \\
\hline 31 & 4-Br,6-F & 20 & $>100$ & $3 x$ & $6-t-\mathrm{Bu}$ & $>100$ & 6.0 \\
\hline
\end{tabular}

a) $\mathrm{EC}_{50}$ was evaluated by the CPE reduction assay. $280 \mathrm{TCID}_{50} / 50 \mu \mathrm{L}$ of MNV and a dilution series of each compound were incubated for 30 min. The mixture was exposed to RAW264.7 cells for $1 \mathrm{~h}$ (in duplicate). b) Cytotoxicity was evaluated by the WST-8 assay. RAW264.7 cells were treated with dilution series of each compound (in triplicate) for $72 \mathrm{~h}$.

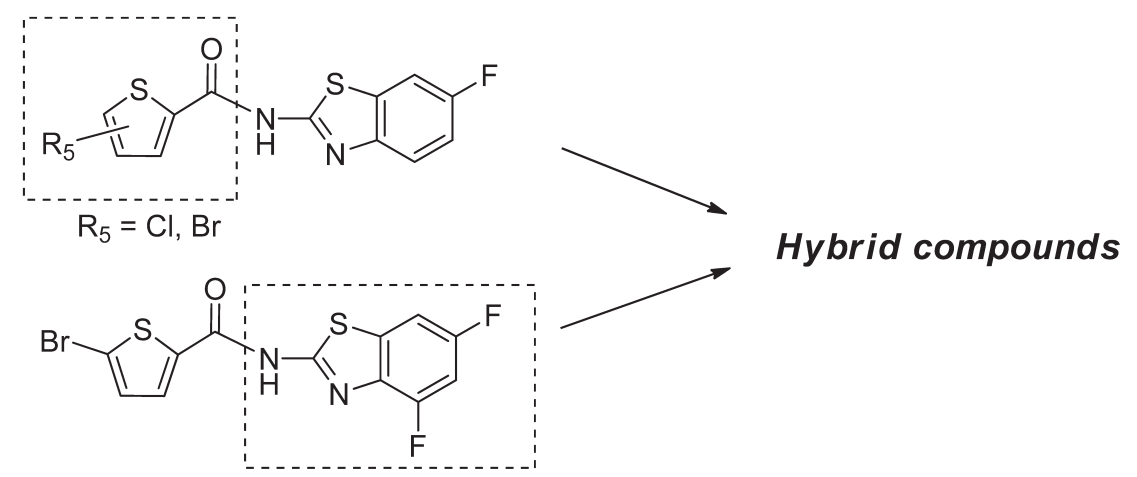

Chart 2. Strategy for Designing Hybrid Compounds

The modified thiophene analogs $\mathbf{2 a}-\mathbf{w}$ were compared with 1 (Table 1). Because unsubstituted analog 2a showed no antiviral activity, the bromine in $\mathbf{1}$ was important for activity. 5-Chloro-thiophene analog $\mathbf{2 b}$ showed similar activity to 5-bromo analog $\mathbf{1}\left(\mathbf{2 b}, \mathrm{EC}_{50}=30 \mu \mathrm{M} ; \mathbf{1}, \mathrm{EC}_{50}=37 \mu \mathrm{M}\right)$. Moreover, 3,5-di-chloro-thiophene analog $\mathbf{2 k}$ had more potent antiviral activity $\left(\mathrm{EC}_{50}=6.6 \mu \mathrm{M}\right)$ than mono-halogenated ana$\operatorname{logs}$ (the $\mathrm{EC}_{50}$ values was $30 \mu \mathrm{M}$ or more). However, halogen groups at the other ring positions, such as 3,5 -di-bromide $\mathbf{2} \mathbf{j}$ or 4,5 -di-chloride $\mathbf{2} \mathbf{m}$, did not increase the antiviral activity. The $\mathrm{CC}_{50}$ values of these compounds was equal to or less than their $\mathrm{EC}_{50}$ values. The other 5-fluorinated, $t$-butylated, 4- or 3-mono-halogenated, 4,5-di-brominated, and 3,4,5-tri-chlorinated analogs $(\mathbf{2} \mathbf{c}-\mathbf{i}, \mathbf{l}$, and $\mathbf{n})$ did not show significant antiviral activity. Furthermore, the alternative heterocyclic analogs (furans $\mathbf{2 0}-\mathbf{q}$, thiazole $\mathbf{2 r}$, and benzothiophene $\mathbf{2 s}$ ) and the thiophene linkage regioisomers $(\mathbf{2 t}-\mathbf{w})$ had almost no antiviral activity. These results suggest that the halogenated thiophene ring conjugated to the amide bond at the 2-position is essential for anti-norovirus activity, and that the chloro groups at the 3and 5-positions are the most effective substituents.

Next, the benzothiazole moiety of $\mathbf{1}$ was modified to elucidate suitable substitutions while retaining the 5-bromo-thio- phene ring (Table 2). Because unsubstituted analog 3a showed no antiviral activity, the fluorine moiety of $\mathbf{1}$ was important for activity. Although 6-chloro-benzothiazole analog 3b showed moderate activity of $56 \mu \mathrm{M}$, the 4 - or 5-mono-halogenated regioisomers $\mathbf{3 d - i}$, and 4- or 6-mono- or 5,6-di-substituted analogs $3 \mathbf{n}-\mathbf{x}\left(\mathrm{Me}, \mathrm{MeO}\right.$, OEt, $\left.\mathrm{NO}_{2}, \mathrm{CF}_{3}, \mathrm{OCF}_{3}, \mathrm{CO}_{2} \mathrm{Et}, t-\mathrm{Bu}\right)$ did not show antiviral activity. $D i$-halogenated benzothiazole analogs $\mathbf{3 j}-\mathbf{m}$ were investigated. Only 4,6-di-fluoro-benzothiazole analog $3 \mathbf{j}$ showed antiviral activity $\left(\mathrm{EC}_{50}=5.6 \mu \mathrm{M}\right)$, which was 6 -fold higher than that of $\mathbf{1}$, and no cytotoxicity at the highest concentration tested. 4-Bromo-6-fluoro analog $\mathbf{3 1}$ showed moderate activity; however, no inhibitory activity was observed in 4,6-di-chloro analog 3k and 5,6-di-fluoro analog $3 \mathbf{m}$. Therefore, 4,6-di-fluoro substitution on the benzothiazole ring increases anti-norovirus activity, and is one of most efficient combinations of halogen substituents.

5-Chlorinated thiophene analog $\mathbf{2 b}, 3,5$ - and 4,5-di-halogenated thiophene analogs $2 \mathbf{j}, \mathbf{k}$, and $\mathbf{m}$, and 4,6-di-fluorinated benzothiazole analog $\mathbf{3} \mathbf{j}$ showed strong antiviral activity (Tables 1, 2). Thus, tri- or tetra-halogenated analogs $\mathbf{4 a - d}$ were synthesized and evaluated as hybrid derivatives, and were expected to show increased activity because of the multiple halogen groups (Chart 2, Table 3). 3,5-Di-bromo-thiophen-4,6- 
$d i$-fluoro-benzothiazole analog $\mathbf{4 b}$ had the most potent antinorovirus activity $\left(\mathrm{EC}_{50}=0.53 \mu \mathrm{M}\right)$, which was 70 -fold greater than that of $\mathbf{1}$, and the other hybrid analogs $\mathbf{4 a}, \mathbf{c}$, and $\mathbf{d}$ also showed potent activity $\left(\mathrm{EC}_{50}=1.1-2.1 \mu \mathrm{M}\right)$. The $\mathrm{CC}_{50}$ values of these compounds were much higher than their $\mathrm{EC}_{50}$ values.

\section{Antiviral Mechanism}

Fifty Percent Tissue Culture Infectious Dose $\left(\mathrm{TCID}_{50}\right)$ Assay with Filtration

To determine the antiviral mechanism, we investigated

Table 3. Antiviral Activity and Cytotoxicity of Tetra-halogenated Hybrid Compounds<smiles>[R]c1sc(C(=O)Nc2nc3c(F)cc(F)cc3s2)c([R8])c1[R7]</smiles>

\begin{tabular}{cccccc}
\multicolumn{6}{c}{ 4a-d } \\
\hline \hline Compound & $\mathrm{R}_{6}$ & $\mathrm{R}_{7}$ & $\mathrm{R}_{8}$ & $\mathrm{EC}_{50}(\mu \mathrm{M})^{a)}$ & $\mathrm{CC}_{50}(\mu \mathrm{M})^{b)}$ \\
\hline $\mathbf{4 a}$ & $\mathrm{Cl}$ & $\mathrm{H}$ & $\mathrm{H}$ & 2.1 & $>100$ \\
$\mathbf{4 b}$ & $\mathrm{Br}$ & $\mathrm{H}$ & $\mathrm{Br}$ & 0.53 & $>100$ \\
$\mathbf{4 c}$ & $\mathrm{Cl}$ & $\mathrm{H}$ & $\mathrm{Cl}$ & 1.1 & $>100$ \\
$\mathbf{4 d}$ & $\mathrm{Cl}$ & $\mathrm{Cl}$ & $\mathrm{H}$ & 1.4 & 31
\end{tabular}

a) $\mathrm{EC}_{50}$ was evaluated by the CPE reduction assay. $280 \mathrm{TCID}_{50} / 50 \mu \mathrm{L}$ of $\mathrm{MNV}$ and a dilution series of each compound were incubated for $30 \mathrm{~min}$. The mixture was exposed to RAW264.7 cells for $1 \mathrm{~h}$ (in duplicate). $b$ ) Cytotoxicity was evaluated by the WST-8 assay. RAW264.7 cells were treated with dilution series of each compound (in triplicate) for $72 \mathrm{~h}$

Table 4. Antiviral Activity of $\mathbf{4 b}$ against MNV Particle

\begin{tabular}{lc}
\hline \hline & $\begin{array}{c}\text { Virus infectivity } \\
\left(\log _{10} \text { TCID }_{50} / \mathrm{mL}\right)\end{array}$ \\
\hline${\left.\text { Control } 1^{a}\right)}_{\text {4b }}$ & 4.8 \\
$2^{\prime}$-CMC & 4.7 \\
GC376 & 4.8 \\
Control $2^{b)}$ & 4.8 \\
$0.02 \%(\mathrm{v} / \mathrm{v})$ sodium hypochlorite & 4.8 \\
\hline
\end{tabular}

Results from two independent experiments and data are expressed as the mean Final concentration of compounds was $225 \mu \mathrm{M}$ and reaction time was $60 \mathrm{~min}$. a) Fetal bovine serum-free medium containing $2.3 \%(\mathrm{v} / \mathrm{v})$ dimethylsulfoxide was used. $b)$ Distilled water was used. whether heterocyclic carboxamide derivatives act on viral particles. A mixture of $\mathbf{4 b}$ and virus were filtered to remove $\mathbf{4 b}$, and then cells were infected with the treated virus. The virus titers were determined by the $\mathrm{TCID}_{50} 50 \%$ tissue culture infectious dose assay. $0.02 \%(\mathrm{v} / \mathrm{v})$ sodium hypochlorite ${ }^{13)}$ as a positive control and 2'-CMC and GC376 as negative controls were used. Although $0.02 \%(\mathrm{v} / \mathrm{v})$ sodium hypochlorite reduced virus infectivity to less than $2.0\left(\log _{10} \mathrm{TCID}_{50} / \mathrm{mL}\right)$, the virus titer was not reduced by $\mathbf{4 b}$ ( 4.8 for virus control and 4.7 for virus treated with 4b) (Table 4). 2'-CMC and GC376 also did not reduce infectivity. This result indicated that $\mathbf{4 b}$ does not act on the viral particle directly.

Time-of-Addition Assay

To identify the mechanism of antiviral activity, $\mathbf{4 b}$ was evaluated by time-of-addition assay. In the simultaneous treatment assay, compounds were mixed with $\mathrm{MNV}$ and incubated for $30 \mathrm{~min}$ at $37^{\circ} \mathrm{C}$, and then cells were exposed to the mixture. After $1 \mathrm{~h}$, the supernatant was replaced with fresh medium. In the post-infection treatment assay, cells were inoculated with $\mathrm{MNV}$ for $1 \mathrm{~h}$ at $37^{\circ} \mathrm{C}$, and then the virus supernatant was replaced with medium containing the compounds and incubated for $72 \mathrm{~h}$ (Fig. 2). Similarly to 2'-CMC and GC376, the antiviral activity of $\mathbf{4 b}$ was preserved when it was added after inoculating the cells with the virus. This result suggests that $\mathbf{4 b}$ does not prevent the early stage of viral infection (virus attachment, entry, and uncoating). Moreover, in both assays, 4b showed more potent antiviral activity than $2^{\prime}$-CMC and GC376, and extending the assay time increased the antiviral activity of $\mathbf{4 b}$ (Table 5).

\section{Discussion}

We used a cell-based screening system to detect antiviral

Table 5. Time-of-Addition Assay Results

\begin{tabular}{cccc}
\hline \hline \multirow{2}{*}{ Conditions } & \multicolumn{3}{c}{$\mathrm{EC}_{50}(\mu \mathrm{M})$} \\
\cline { 2 - 4 } & $\mathbf{4 b}$ & $2^{\prime}-\mathrm{CMC}$ & $\mathrm{GC} 376$ \\
\hline Simultaneous treatment $^{a)}$ & 0.53 & 56 & $>100$ \\
Post-infection treatment $^{b)}$ & 0.041 & 4.6 & 68 \\
\hline
\end{tabular}

Results from two independent experiments performed in duplicate. Effect of changing the infection order. $a$ ) Compounds and virus were exposed to cells simultaneously for $1 \mathrm{~h} . b$ ) After viral infection for $1 \mathrm{~h}$, cells were treated with compounds for $72 \mathrm{~h}$.

\section{Simultaneous treatment}

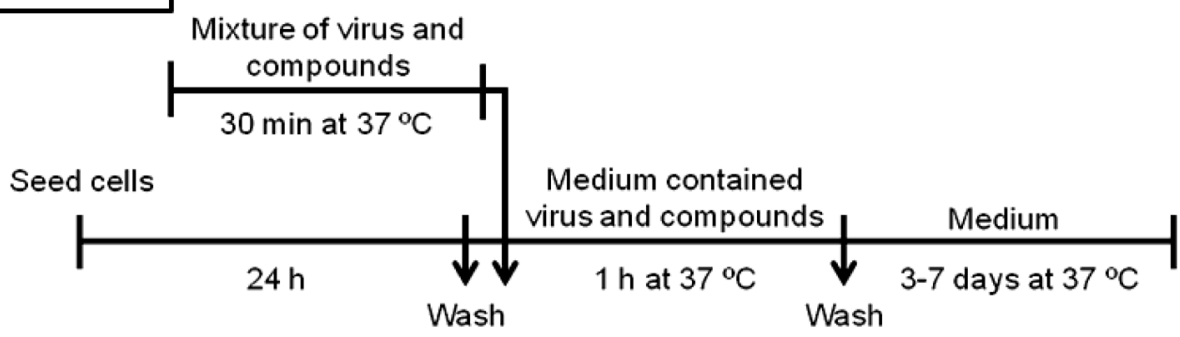

Post-infection treatment

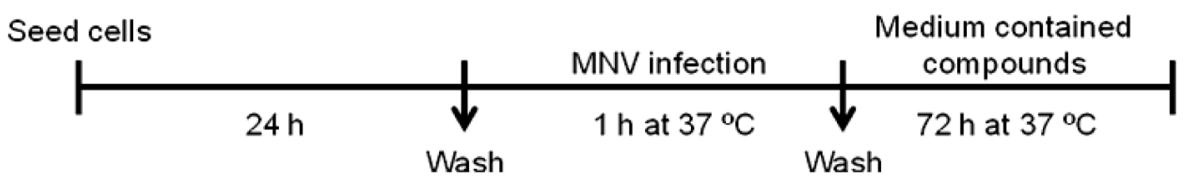

Fig. 2. Protocols for Time-of-Addition Assays 
compounds that affect intracellular viral replication and the viral particle directly. We screened approximately 2000 compounds from our chemical library and identified 5-bromo- $\mathrm{N}$ (6-fluorobenzo $[d]$ thiazol-2-yl)thiophene-2-carboxamide (1) as an anti-norovirus agent with an $\mathrm{EC}_{50}$ of $37 \mu \mathrm{M}$. We conducted SAR studies on thiophene and benzothiazole analogs of $\mathbf{1}$, and identified derivatives that showed more potent antiviral activity. For instance, 5-chloro-thiophene $2 \mathbf{b}\left(\mathrm{EC}_{50}=30 \mu \mathrm{M}\right)$, 3,5-di-bromo-thiophene $\mathbf{2} \mathbf{j}\left(\mathrm{EC}_{50}=24 \mu \mathrm{M}\right), 3,5$ - and 4,5-di-chloro-thiophenes $\mathbf{2 k}$ and $\mathbf{m}\left(\mathrm{EC}_{50}=6.6\right.$ and $24 \mu \mathrm{M}$, respectively), and 4,6-di-fluoro-benzothiazole $\mathbf{3 j}\left(\mathrm{EC}_{50}=5.6 \mu \mathrm{M}\right)$ were potent antiviral agents. Although there were not obvious substituent effects on the thiophene or the benzothiazole core structure, the SAR results showed that the $d i$-halogenated analogs were more potent than the mono-halogenated analogues (e.g., $3 \mathbf{j}$, $\mathrm{EC}_{50}=5.6 \mu \mathrm{M}$ vs. 1, $\left.\mathrm{EC}_{50}=37 \mu \mathrm{M}\right)$. We synthesized hybrid compounds $\mathbf{4 a}-\mathbf{d}$ by combining structural features of $\mathbf{2} \mathbf{b}, \mathbf{j}$, $\mathbf{k}, \mathbf{m}$, and $\mathbf{3 j}$. The combination of bromination at the $3-$ and 5 -positions on the thiophene ring (from $\mathbf{2} \mathbf{j}$ ) and fluorination of the 4- and 6-positions on the benzothiazole ring (from $\mathbf{3 j}$ ) gave a more potent antiviral agent $\left(\mathbf{4 b}, \mathrm{EC}_{50}=0.53 \mu \mathrm{M}\right)$ than $\mathbf{4 c}$ $\left(\mathrm{EC}_{50}=1.1 \mu \mathrm{M}\right)$, synthesized from the combination of $\mathbf{2} \mathbf{k}$ and 3j, which possessed the highest activities. Physicochemical properties of the optimal balanced thiophene-benzothiazole carboxamide core structure such as hydrophobicity, electron density, and steric effect might be important for potent antiviral activity. We performed a $\mathrm{TCID}_{50}$ assay with filtration to investigate whether heterocyclic carboxamide derivatives act directly on the viral particles. The virus infectivity was not reduced by treatment with $\mathbf{4 b}$, which suggested that $\mathbf{4 b}$ does not act on viral particles directly. Potential therapeutic intervention stages other than direct action on viral particles are: (1) early stages of viral infection (virus attachment, entry, and uncoating); (2) viral replication ( $\mathrm{RdRp}$ and 3CL pro); and (3) late stages of viral infection (virion assembly and release). ${ }^{7,8)}$ We performed a time-of-addition assay to identify whether 4b inhibits the early stage of viral infection. Comparing $4 \mathbf{b}$ with inhibitors of intracellular viral replication, 2'-CMC and GC376, showed that they exerted similar antiviral effects. These results suggest that heterocyclic carboxamide derivatives act on intracellular viral replication or the late stages of viral infection. In addition, $\mathbf{4 b}$ showed antiviral activity at a lower concentration than $2^{\prime}$-CMC and GC376. To investigate viral replication, we evaluated the inhibitory activity of $\mathbf{4 b}$ against MNV protease by using a rabbit reticulocyte lysate in vitro translation system. ${ }^{14)}$ No inhibition was detected (data not shown). The anti-MNV mechanism of $\mathbf{4 b}$ is under further investigation. Because this compound has a low $\mathrm{EC}_{50}$ value, it may be a useful tool for identifying target proteins and a good lead compound for developing effective therapeutics and prophylactics for norovirus.

\section{Experimental}

General Chemical Procedure Melting points (mp) of the compounds were obtained using Mettler-toledo Excellence MP70 melting-point apparatus. ${ }^{1} \mathrm{H}-$ and ${ }^{13} \mathrm{C}-\mathrm{NMR}$ spectra were recorded on a JEOL AL-400 (at 400 and $100 \mathrm{MHz}$, respectively) by using dimethylsulfoxide (DMSO)- $d_{6}$ with tetramethylsilane (TMS) as the internal standard. The spin multiplicities are indicated by the following symbols s (singlet), $\mathrm{d}$ (doublet), dd (doublet of doublets), t (triplet), dt (doublet of triplets), ddd (doublet of doublet of doublets), ddt (doublet of doublet of triplets), q (quartet), $\mathrm{m}$ (multiplet). Chemical shift $(\delta)$ is expressed in ppm. LC/MS analyses were performed with Waters 2767 sample manager, 2996 photodiode array detector and 600 controller ZQ. Electrospray ionization (ESI) MS spectra were recorded at $60 \mathrm{eV}$ on a Waters ZQ2000. A Cosmosil 5C18-ARII column $(2.0 \times 50 \mathrm{~mm}$, Nacalai Tesque) was employed with a linear gradient of $\mathrm{CH}_{3} \mathrm{CN}$ containing $0.05 \%$ (v/v) trifluoroacetic acid (TFA) at a flow rate of $1 \mathrm{~mL} / \mathrm{min}$, and eluting products were detected by UV at $254 \mathrm{~nm}$. The purity of the compounds was determined by HPLC analysis. Reactions were monitored by TLC using E. MERCK silica gel $60 \mathrm{~F}_{254}$ glass plate. Preparative layer chromatography was performed using E. MERCK PLC silica gel $60 \mathrm{~F}_{254}, 2 \mathrm{~mm}$ glass plate. Column chromatography was carried out on FUJI SILYSIA CHEMICAL CHROMATOREX NH DM1020 and/ or silica gel. 2'-CMC was purchased from Sigma-Aldrich. The commercial bleach (Oyalox), which was contained 6\% sodium hypochlorite, was purchased locally. GC376 was synthesized by a reported procedure. ${ }^{15)}$

5-Bromo- $N$-(6-fluorobenzo $[d]$ thiazol-2-yl)thiophene2-carboxamide (1) A mixture of 5-bromothiophene-2-carboxylic acid $(203 \mathrm{mg}, 0.98 \mathrm{mmol})$, 6-fluorobenzo[d]thiazol-2amine $(188 \mathrm{mg}, 1.12 \mathrm{mmol})$, DMAP $(133 \mathrm{mg}, 1.09 \mathrm{mmol})$ and $\mathrm{EDC} \cdot \mathrm{HCl}(208 \mathrm{mg}, 1.08 \mathrm{mmol})$ in $\mathrm{CH}_{2} \mathrm{Cl}_{2}(2 \mathrm{~mL})$ was stirred for $4 \mathrm{~h}$ at room temperature $(\mathrm{rt})$. The reaction mixture was concentrated and the residue was washed several times with cold $\mathrm{MeOH}$. The solid was crystallized from $\mathrm{MeOH}$ to give $1(67 \mathrm{mg}, 19 \%)$ as light yellow powder. $\mathrm{mp}: 257-258^{\circ} \mathrm{C}$. ${ }^{1} \mathrm{H}-\mathrm{NMR}\left(\mathrm{DMSO}-d_{6}\right) \delta: 7.32(1 \mathrm{H}, \mathrm{dt}, J=8.8,2.4 \mathrm{~Hz}), 7.43(1 \mathrm{H}$, $\mathrm{d}, J=4.8 \mathrm{~Hz}), 7.77(1 \mathrm{H}, \mathrm{dd}, J=8.8,4.8 \mathrm{~Hz}), 7.93(1 \mathrm{H}, \mathrm{dd}, J=8.8$, $2.4 \mathrm{~Hz}), 8.09(1 \mathrm{H}, \mathrm{d}, J=3.6 \mathrm{~Hz}) .{ }^{13} \mathrm{C}-\mathrm{NMR}\left(\mathrm{DMSO}-d_{6}\right) \delta: 108.3$ (d, $J=27.3 \mathrm{~Hz}), 114.4$ (d, $J=24.8 \mathrm{~Hz}), 120.1,121.1,132.2,132.3$, 132.5 (d, $J=9.9 \mathrm{~Hz}), 138.9,144.5,158.7$ (d, $J=240.6 \mathrm{~Hz}), 158.8$, 159.8. HPLC purity: $>99 \%$, ESI-MS $m / z: 357[\mathrm{M}+\mathrm{H}]^{+}$.

$\mathrm{N}$-(6-Fluorobenzo[d]thiazol-2-yl)thiophene-2-carboxamide (2a) A mixture of thiophene-2-carboxylic acid (143 mg, $1.12 \mathrm{mmol}), 6$-fluorobenzo[d]thiazol-2-amine $(207 \mathrm{mg}$, $1.23 \mathrm{mmol})$, DMAP $(155 \mathrm{mg}, 1.27 \mathrm{mmol})$ and $\mathrm{EDC} \cdot \mathrm{HCl}$ (230 mg, $1.20 \mathrm{mmol})$ in $\mathrm{CH}_{2} \mathrm{Cl}_{2}(2 \mathrm{~mL})$ was stirred overnight at rt. The reaction mixture was diluted with $\mathrm{CH}_{2} \mathrm{Cl}_{2}$ and washed with $2 \mathrm{~N} \mathrm{HCl}, \mathrm{H}_{2} \mathrm{O}$, and brine. The organic layer was dried over $\mathrm{MgSO}_{4}$ and concentrated. The residue was washed several times with $\mathrm{CHCl}_{3}$ and $\mathrm{MeOH}$ to give 2a (126 mg, 40\%) as white powder. ${ }^{1} \mathrm{H}-\mathrm{NMR}$ (DMSO- $\left.d_{6}\right) \delta$ : 7.28-7.35 $(2 \mathrm{H}, \mathrm{m})$, $7.79(1 \mathrm{H}, \mathrm{dd}, J=8.8,4.8 \mathrm{~Hz}), 7.94(1 \mathrm{H}, \mathrm{dd}, J=8.8,2.4 \mathrm{~Hz}), 8.03$ $(1 \mathrm{H}, \mathrm{d}, J=4.8 \mathrm{~Hz}), 8.32(1 \mathrm{H}, \mathrm{d}, J=3.2 \mathrm{~Hz}) .{ }^{13} \mathrm{C}-\mathrm{NMR}$ (DMSO$\left.d_{6}\right) \delta: 108.2(\mathrm{~d}, J=28.1 \mathrm{~Hz}), 114.3(\mathrm{~d}, J=24.0 \mathrm{~Hz}), 121.4,128.7$, $131.5,132.7$ (d, $J=8.2 \mathrm{~Hz}), 134.2,136.9,145.1,158.5,158.7$ (d, $J=240.6 \mathrm{~Hz}), 160.6$. HPLC purity: $>99 \%$, ESI-MS $\mathrm{m} / \mathrm{z} 279$ $[\mathrm{M}+\mathrm{H}]^{+}$.

5-Chloro- $N$-(6-fluorobenzo $[d]$ thiazol-2-yl)thiophene2-carboxamide (2b) A mixture of 5-chlorothiophene-2-carboxylic acid (163 mg, $1.00 \mathrm{mmol})$, 6-fluorobenzo[d]thiazol-2amine $(185 \mathrm{mg}, 1.10 \mathrm{mmol})$, DMAP $(183 \mathrm{mg}, 1.50 \mathrm{mmol})$ and $\mathrm{EDC} \cdot \mathrm{HCl}(287 \mathrm{mg}, 1.50 \mathrm{mmol})$ in $\mathrm{CH}_{2} \mathrm{Cl}_{2}(2 \mathrm{~mL})$ was stirred overnight at $\mathrm{rt}$. The reaction mixture was diluted with $\mathrm{CH}_{2} \mathrm{Cl}_{2}$ and washed with $2 \mathrm{~N} \mathrm{HCl}, \mathrm{H}_{2} \mathrm{O}$, and brine. The organic layer was dried over $\mathrm{MgSO}_{4}$ and concentrated. The residue was purified by $\mathrm{NH}$-silica-gel column chromatography (eluent: $\left.\mathrm{CH}_{2} \mathrm{Cl}_{2} / \mathrm{MeOH}=10: 1\right)$ and the solid was washed several times 
with $\mathrm{CHCl}_{3}$ and $\mathrm{MeOH}$ to give $2 \mathbf{b}(136 \mathrm{mg}, 43 \%)$ as white powder. mp: $244-246^{\circ} \mathrm{C}$. ${ }^{1} \mathrm{H}-\mathrm{NMR}$ (DMSO- $d_{6}$ ) $\delta$ : $7.30-7.35$ $(2 \mathrm{H}, \mathrm{m}), 7.77(1 \mathrm{H}, \mathrm{dd}, J=8.8,4.8 \mathrm{~Hz}), 7.93(1 \mathrm{H}, \mathrm{dd}, J=8.8$, $2.4 \mathrm{~Hz}), 8.15(1 \mathrm{H}, \mathrm{s}) .{ }^{13} \mathrm{C}-\mathrm{NMR}$ (DMSO- $\left.d_{6}\right) \delta: 108.3(\mathrm{~d}$, $J=27.3 \mathrm{~Hz}), 114.4$ (d, $J=24.8 \mathrm{~Hz}), 121.3(\mathrm{~d}, J=24.8 \mathrm{~Hz}), 128.8$, 131.5, 131.8, 132.6, 136.0, 145.1, 158.7 (d, $J=240.5 \mathrm{~Hz}$ ), 159.0, 159.6. HPLC purity: 98\%, ESI-MS $m / z 313[\mathrm{M}+\mathrm{H}]^{+}$.

5-Fluoro- $N$-(6-fluorobenzo $[d]$ thiazol-2-yl)thiophene2-carboxamide (2c) According to the same procedure used for 2a, starting from 5-fluorothiophene-2-carboxylic acid $(146 \mathrm{mg}, \quad 1.00 \mathrm{mmol})$ and 6-fluorobenzo[ $d]$ thiazol-2-amine (185 mg, $1.10 \mathrm{mmol}), 2 \mathrm{c}(76 \mathrm{mg}, 26 \%)$ was obtained as white powder. ${ }^{1} \mathrm{H}-\mathrm{NMR}$ (DMSO- $\left.d_{6}\right) \delta$ : $6.97(1 \mathrm{H}, \mathrm{dd}, J=4.8,1.6 \mathrm{~Hz})$, $7.32(1 \mathrm{H}, \mathrm{dt}, J=8.8,2.4 \mathrm{~Hz}), 7.77(1 \mathrm{H}, \mathrm{dd}, J=8.8,4.8 \mathrm{~Hz})$, $7.92(1 \mathrm{H}, \mathrm{dd}, J=8.8,2.4 \mathrm{~Hz}), 8.07(1 \mathrm{H}, \mathrm{s}) .{ }^{13} \mathrm{C}-\mathrm{NMR}$ (DMSO$\left.d_{6}\right) \delta: 108.3(\mathrm{~d}, J=27.3 \mathrm{~Hz}), 110.9(\mathrm{~d}, J=11.5 \mathrm{~Hz}), 114.3(\mathrm{~d}$, $J=24.0 \mathrm{~Hz}), 121.1$ (d, $J=9.1 \mathrm{~Hz}), 126.5,129.8$ (d, $J=4.1 \mathrm{~Hz})$, 132.6 (d, $J=8.3 \mathrm{~Hz}$ ), 144.9, 158.6, 158.7 (d, $J=240.6 \mathrm{~Hz}), 160.3$, 169.1 (d, $J=293.5 \mathrm{~Hz}$ ). HPLC purity: >99\%, ESI-MS $\mathrm{m} / \mathrm{z} 297$ $[\mathrm{M}+\mathrm{H}]^{+}$.

5-(tert-Butyl)- $N$-(6-fluorobenzo[ $d]$ thiazol-2-yl)thiophene2-carboxamide (2d) A mixture of 5-(tert-butyl)thiophene-2carboxylic acid (184 mg, $1.00 \mathrm{mmol})$, 6-fluorobenzo[d]thiazol-2amine $(186 \mathrm{mg}, 1.10 \mathrm{mmol})$, DMAP $(183 \mathrm{mg}, 1.50 \mathrm{mmol})$ and $\mathrm{EDC} \cdot \mathrm{HCl}(287 \mathrm{mg}, 1.50 \mathrm{mmol})$ in $\mathrm{CH}_{2} \mathrm{Cl}_{2}(2 \mathrm{~mL})$ was stirred overnight at $\mathrm{rt} . \mathrm{CH}_{2} \mathrm{Cl}_{2}$ and $2 \mathrm{~N} \mathrm{HCl}$ were added, the precipitate was filtered and washed several times with $\mathrm{CH}_{2} \mathrm{Cl}_{2}$ and $\mathrm{MeOH}$ to give 2d (195mg, 58\%) as white powder. ${ }^{1} \mathrm{H}-\mathrm{NMR}$ $\left(\mathrm{DMSO}_{6}\right) \delta: 1.39(9 \mathrm{H}, \mathrm{s}), 7.09(1 \mathrm{H}, \mathrm{dd}, J=3.6,0.8 \mathrm{~Hz}), 7.31$ $(1 \mathrm{H}, \mathrm{dt}, J=8.8,2.4 \mathrm{~Hz}), 7.77(1 \mathrm{H}, \mathrm{dd}, J=8.8,4.8 \mathrm{~Hz}), 7.92(1 \mathrm{H}$, dd, $J=8.8,2.4 \mathrm{~Hz}), 8.14(1 \mathrm{H}, \mathrm{d}, J=3.6 \mathrm{~Hz}),{ }^{13} \mathrm{C}-\mathrm{NMR}$ (DMSO$\left.d_{6}\right) \delta: 31.8,34.8,108.2(\mathrm{~d}, J=27.2 \mathrm{~Hz}), 114.2(\mathrm{~d}, J=24.0 \mathrm{~Hz})$, $121.3(\mathrm{~d}, J=9.1 \mathrm{~Hz}), 123.8,131.6,132.8(\mathrm{~d}, J=9.1 \mathrm{~Hz}), 133.3$, $145.3,158.7,158.7$ (d, $J=239.7 \mathrm{~Hz}), 160.5,165.4$. HPLC purity: $>99 \%$, ESI-MS $m / z 335[\mathrm{M}+\mathrm{H}]^{+}$.

4-Chloro- $N$-(6-fluorobenzo $[d]$ thiazol-2-yl)thiophene2-carboxamide (2e) According to the same procedure used for 2d, starting from 4-chlorothiophene-2-carboxylic acid $(163 \mathrm{mg}, \quad 1.00 \mathrm{mmol})$ and 6-fluorobenzo[d]thiazol-2-amine (185 mg, $1.10 \mathrm{mmol}), 2 \mathrm{e}(182 \mathrm{mg}, 58 \%)$ was obtained as white powder. ${ }^{1} \mathrm{H}-\mathrm{NMR}$ (DMSO- $\left.d_{6}\right) \delta: 7.33(1 \mathrm{H}, \mathrm{dt}, J=8.8,2.4 \mathrm{~Hz})$, $7.79(1 \mathrm{H}, \mathrm{dd}, J=8.8,4.8 \mathrm{~Hz}), 7.94(1 \mathrm{H}, \mathrm{dd}, J=8.8,2.4 \mathrm{~Hz})$, $8.06(1 \mathrm{H}, \mathrm{s}), 8.26(1 \mathrm{H}, \mathrm{s}) .{ }^{13} \mathrm{C}-\mathrm{NMR}\left(\mathrm{DMSO}-d_{6}\right) \delta: 108.3(\mathrm{~d}$, $J=26.4 \mathrm{~Hz}), 114.5$ (d, $J=24.8 \mathrm{~Hz}), 121.4(\mathrm{~d}, J=10.7 \mathrm{~Hz}), 124.4$, 129.1, 130.7, 132.7, 137.5 (d, $J=9.1 \mathrm{~Hz}), 144.9,158.5,158.8$ (d, $J=240.6 \mathrm{~Hz}$ ), 160.6. HPLC purity: $>99 \%$, ESI-MS $\mathrm{m} / \mathrm{z} 313$ $[\mathrm{M}+\mathrm{H}]^{+}$.

4-Bromo- $N$-(6-fluorobenzo $[d]$ thiazol-2-yl)thiophene2-carboxamide (2f) A mixture of 4-bromothiophene-2-carboxylic acid $(207 \mathrm{mg}, 1.00 \mathrm{mmol})$, 6-fluorobenzo[d]thiazol-2amine $(185 \mathrm{mg}, 1.10 \mathrm{mmol})$, DMAP $(184 \mathrm{mg}, 1.51 \mathrm{mmol})$ and $\mathrm{EDC} \cdot \mathrm{HCl}(290 \mathrm{mg}, 1.51 \mathrm{mmol})$ in $\mathrm{CH}_{2} \mathrm{Cl}_{2}(2 \mathrm{~mL})$ was stirred overnight at rt. $\mathrm{CH}_{2} \mathrm{Cl}_{2}$ and $2 \mathrm{~N} \mathrm{HCl}$ were added, the precipitate was filtered and washed several times with $\mathrm{CHCl}_{3}$ and $\mathrm{MeOH}$ to give $2 \mathrm{f}(150 \mathrm{mg}, 42 \%)$ as white powder. ${ }^{1} \mathrm{H}-\mathrm{NMR}$ $\left(\mathrm{DMSO}-d_{6}\right) \delta: 7.33(1 \mathrm{H}, \mathrm{dt}, J=8.8,2.4 \mathrm{~Hz}), 7.79(1 \mathrm{H}, \mathrm{dd}$, $J=8.8,4.8 \mathrm{~Hz}), 7.94(1 \mathrm{H}, \mathrm{dd}, J=8.8,2.4 \mathrm{~Hz}), 8.15(1 \mathrm{H}, \mathrm{s}), 8.30$ $(1 \mathrm{H}, \mathrm{s}) .{ }^{13} \mathrm{C}-\mathrm{NMR}$ (DMSO-d $\left.{ }_{6}\right) \delta: 108.3(\mathrm{~d}, J=27.2 \mathrm{~Hz}), 109.6$, $114.4(\mathrm{~d}, J=24.0 \mathrm{~Hz}), 121.4(\mathrm{~d}, J=11.5 \mathrm{~Hz}), 131.6,132.6$ (d, $J=9.0 \mathrm{~Hz}), 133.1,138.2(\mathrm{~d}, J=5.8 \mathrm{~Hz}), 145.0,158.5,158.8$ (d, $J=239.8 \mathrm{~Hz}$ ), 159.4. HPLC purity: $>99 \%$, ESI-MS $\mathrm{m} / \mathrm{z} 357$

\section{$[\mathrm{M}+\mathrm{H}]^{+}$.}

3-Fluoro- $N$-(6-fluorobenzo[d]thiazol-2-yl)thiophene2-carboxamide (2g) According to the same procedure used for $\mathbf{2 b}$, starting from 3-fluorothiophene-2-carboxylic acid $(147 \mathrm{mg}, \quad 1.00 \mathrm{mmol})$ and 6-fluorobenzo[d]thiazol-2-amine (185 mg, $1.10 \mathrm{mmol}), 2 \mathrm{~g}(120 \mathrm{mg}, 40 \%)$ was obtained as white powder. ${ }^{1} \mathrm{H}-\mathrm{NMR}\left(\mathrm{DMSO}-d_{6}\right) \delta: 7.19(1 \mathrm{H}, \mathrm{d}, J=4.8 \mathrm{~Hz}), 7.33$ $(1 \mathrm{H}, \mathrm{dt}, J=8.8,2.4 \mathrm{~Hz}), 7.70(1 \mathrm{H}, \mathrm{s}), 7.91(1 \mathrm{H}, \mathrm{dd}, J=8.8$, $2.4 \mathrm{~Hz}), 7.96(1 \mathrm{H}, \mathrm{s}) .{ }^{13} \mathrm{C}-\mathrm{NMR}$ (DMSO-d $\left.d_{6}\right) \delta: 108.6(\mathrm{~d}$, $J=26.5 \mathrm{~Hz}), 114.5(\mathrm{~d}, J=24.8 \mathrm{~Hz}), 116.1,118.7$ (d, $J=25.6 \mathrm{~Hz})$, 119.9, 131.7, 131.8, 141.7, 156.6, 157.9 (d, J=271.1 Hz), 158.8 (d, $J=241.4 \mathrm{~Hz}$ ), 160.8. HPLC purity: >99\%, ESI-MS $\mathrm{m} / z 297$ $[\mathrm{M}+\mathrm{H}]^{+}$.

3-Chloro- $\mathrm{N}$-(6-fluorobenzo[ $d]$ thiazol-2-yl)thiophene2-carboxamide (2h) According to the same procedure used for 2a, starting from 3-chlorothiophene-2-carboxylic acid $(163 \mathrm{mg}, \quad 1.00 \mathrm{mmol})$ and 6-fluorobenzo $[d]$ thiazol-2-amine (185 mg, $1.10 \mathrm{mmol}), \mathbf{2 h}(131 \mathrm{mg}, 42 \%)$ was obtained as white powder. ${ }^{1} \mathrm{H}-\mathrm{NMR}$ (DMSO- $\left.d_{6}\right) \delta: 7.25(1 \mathrm{H}, \mathrm{d}, J=4.8 \mathrm{~Hz}), 7.33$ $(1 \mathrm{H}, \mathrm{dt}, J=8.8,2.4 \mathrm{~Hz}), 7.66(1 \mathrm{H}, \mathrm{s}), 7.91(1 \mathrm{H}, \mathrm{dd}, J=8.8$, $2.4 \mathrm{~Hz}), 7.97(1 \mathrm{H}, \mathrm{d}, J=4.8 \mathrm{~Hz}) \cdot{ }^{13} \mathrm{C}-\mathrm{NMR}\left(\mathrm{DMSO}-d_{6}\right) \delta: 108.8$ (d, $J=27.3 \mathrm{~Hz}), 114.6$ (d, $J=24.8 \mathrm{~Hz}), 118.9$ (d, $J=9.0 \mathrm{~Hz}), 127.7$, 128.0, 129.8, 130.0, 131.0, 131.3, 140.4, 158.7 (d, $J=239.7 \mathrm{~Hz}$ ), 161.4. HPLC purity: $>99 \%$, ESI-MS $m / z 313[\mathrm{M}+\mathrm{H}]^{+}$.

3-Bromo- $N$-(6-fluorobenzo[ $d]$ thiazol-2-yl)thiophene2-carboxamide (2i) According to the same procedure used for 2a, starting from 3-bromothiophene-2-carboxylic acid $(207 \mathrm{mg}, \quad 1.00 \mathrm{mmol})$ and 6-fluorobenzo[d]thiazol-2-amine (185 mg, $1.10 \mathrm{mmol}), 2 \mathbf{i}(41 \mathrm{mg}, 11 \%)$ was obtained as white powder. ${ }^{1} \mathrm{H}-\mathrm{NMR}$ (DMSO- $\left.d_{6}\right) \delta$ : $7.29(1 \mathrm{H}, \mathrm{d}, J=5.2 \mathrm{~Hz}), 7.35$ $(1 \mathrm{H}, \mathrm{dt}, J=8.8,2.4 \mathrm{~Hz}), 7.66(1 \mathrm{H}, \mathrm{s}), 7.91(1 \mathrm{H}, \mathrm{dd}, J=8.8$, $2.4 \mathrm{~Hz}), 7.95(1 \mathrm{H}, \mathrm{d}, J=5.2 \mathrm{~Hz}) .{ }^{13} \mathrm{C}-\mathrm{NMR}\left(\mathrm{DMSO}-d_{6}\right) \delta: 108.9$ $(\mathrm{d}, J=26.4 \mathrm{~Hz}), 113.9,114.6(\mathrm{~d}, J=24.8 \mathrm{~Hz}), 119.2,130.9,131.5$, 132.0, 132.5, 132.8, 141.7, $158.7(\mathrm{~d}, J=239.7 \mathrm{~Hz}), 163.0$. HPLC purity: 99\%, ESI-MS m/z $357[\mathrm{M}+\mathrm{H}]^{+}$.

3,5-Dibromo- $N$-(6-fluorobenzo[ $[d]$ thiazol-2-yl)thiophene2-carboxamide (2j) According to the same procedure used for 2a, starting from 3,5-dibromothiophene-2-carboxylic acid $(286 \mathrm{mg}, \quad 1.00 \mathrm{mmol})$ and 6-fluorobenzo[d]thiazol-2-amine (185 mg, $1.10 \mathrm{mmol}), \mathbf{2 j}(266 \mathrm{mg}, 61 \%)$ was obtained as light yellow powder. mp: $212-213^{\circ} \mathrm{C} .{ }^{1} \mathrm{H}-\mathrm{NMR}$ (DMSO- $d_{6}$ ) $\delta: 7.34$ $(1 \mathrm{H}, \mathrm{dt}, J=8.8,2.4 \mathrm{~Hz}), 7.49(1 \mathrm{H}, \mathrm{s}), 7.56(1 \mathrm{H}, \mathrm{s}), 7.88(1 \mathrm{H}, \mathrm{dd}$, $J=8.8,2.4 \mathrm{~Hz}) .{ }^{13} \mathrm{C}-\mathrm{NMR}\left(\mathrm{DMSO}-d_{6}\right) \delta: 109.2(\mathrm{~d}, J=28.9 \mathrm{~Hz})$, 113.6, 114.8 (d, $J=29.4 \mathrm{~Hz}), 116.6$ (d, $J=11.5 \mathrm{~Hz}), 118.2,129.6$ (d, $J=4.1 \mathrm{~Hz}), 134.6(\mathrm{~d}, J=11.6 \mathrm{~Hz}), 135.4,135.7,158.7$ (d, $J=248.0 \mathrm{~Hz}), 164.0,164.6$. HPLC purity: $>99 \%$, ESI-MS $\mathrm{m} / \mathrm{z}$ $435[\mathrm{M}+\mathrm{H}]^{+}$.

3,5-Dichloro- $N$-(6-fluorobenzo[d] thiazol-2-yl)thiophene2-carboxamide (2k) According to the same procedure used for 2d, starting from 3,5-dichlorothiophene-2-carboxylic acid $(197 \mathrm{mg}, \quad 1.00 \mathrm{mmol})$ and 6-fluorobenzo $[d]$ thiazol-2-amine (185 mg, $1.10 \mathrm{mmol}), \mathbf{2 k}(192 \mathrm{mg}, 55 \%)$ was obtained as beige powder. mp: $259-261^{\circ} \mathrm{C}$. ${ }^{1} \mathrm{H}-\mathrm{NMR}\left(\mathrm{DMSO}-d_{6}\right) \delta$ : $7.29(1 \mathrm{H}$, $\mathrm{dt}, J=8.8,2.4 \mathrm{~Hz}), 7.73(1 \mathrm{H}, \mathrm{dd}, J=8.8,4.8 \mathrm{~Hz}), 7.85(1 \mathrm{H}, \mathrm{dd}$, $J=8.8,2.4 \mathrm{~Hz}), 8.17(1 \mathrm{H}, \mathrm{s}) .{ }^{13} \mathrm{C}-\mathrm{NMR}\left(\mathrm{DMSO}-d_{6}\right) \delta: 108.4$ (dd, $J=27.2,8.0 \mathrm{~Hz}), 114.5$ (dd, $J=24.8,8.0 \mathrm{~Hz}), 120.7$ (dd, $J=15.6,4.1 \mathrm{~Hz}), 124.1,130.3,130.7,132.3$ (d, $J=6.6 \mathrm{~Hz}), 134.6$, $135.1(\mathrm{~d}, J=4.9 \mathrm{~Hz}), 142.3,158.8(\mathrm{~d}, J=240.6 \mathrm{~Hz}), 159.9$. HPLC purity: 99\%, ESI-MS m/z $347[\mathrm{M}+\mathrm{H}]^{+}$.

4,5-Dibromo- $N$-(6-fluorobenzo[ $d]$ thiazol-2-yl)thiophene2-carboxamide (21) According to the same procedure used 
for 2d, starting from 4,5-dibromothiophene-2-carboxylic acid $(287 \mathrm{mg}, \quad 1.00 \mathrm{mmol})$ and 6-fluorobenzo[d]thiazol-2-amine (185 mg, $1.10 \mathrm{mmol}), 21$ (321 mg, 74\%) was obtained as white powder. ${ }^{1} \mathrm{H}-\mathrm{NMR}\left(\mathrm{DMSO}-d_{6}\right) \delta: 7.29(1 \mathrm{H}, \mathrm{dt}, J=8.8,2.4 \mathrm{~Hz})$, $7.74(1 \mathrm{H}, \mathrm{dd}, J=8.8,4.8 \mathrm{~Hz}), 7.86(1 \mathrm{H}, \mathrm{dd}, J=8.8,2.4 \mathrm{~Hz}), 8.16$ $(1 \mathrm{H}, \mathrm{s}) .{ }^{13} \mathrm{C}-\mathrm{NMR}$ (DMSO- $\left.d_{6}\right) \delta: 108.4(\mathrm{~d}, J=27.3 \mathrm{~Hz}), 114.5$ (d, $J=24.8 \mathrm{~Hz}), 114.7,119.3,121.4,129.8,132.3,133.2,138.5$, 145.7, 158.8 (d, $J=236.4 \mathrm{~Hz}), 159.1$. HPLC purity: 96\%, ESIMS $m / z 435[\mathrm{M}+\mathrm{H}]^{+}$.

4,5-Dichloro- $N$-(6-fluorobenzo[ $d]$ thiazol-2-yl)thiophene2-carboxamide (2m) According to the same procedure used for $\mathbf{2 d}$, starting from 4,5-dichlorothiophene-2-carboxylic acid $(197 \mathrm{mg}, \quad 1.00 \mathrm{mmol})$ and 6-fluorobenzo[d]thiazol-2-amine (185 mg, $1.10 \mathrm{mmol}), 2 \mathrm{~m}(207 \mathrm{mg}, 60 \%)$ was obtained as white powder. mp: $260-261^{\circ} \mathrm{C} .{ }^{1} \mathrm{H}-\mathrm{NMR}\left(\mathrm{DMSO}-d_{6}\right) \delta$ : $7.30(1 \mathrm{H}$, dt, $J=8.8,2.4 \mathrm{~Hz}), 7.73(1 \mathrm{H}, \mathrm{dd}, J=8.8,4.8 \mathrm{~Hz}), 7.86(1 \mathrm{H}, \mathrm{dd}$, $J=8.8,2.4 \mathrm{~Hz}), 8.18(1 \mathrm{H}, \mathrm{s}) .{ }^{13} \mathrm{C}-\mathrm{NMR}\left(\mathrm{DMSO}-d_{6}\right) \delta: 108.0(\mathrm{~d}$, $J=27.2 \mathrm{~Hz}), 114.1(\mathrm{~d}, J=24.8 \mathrm{~Hz}), 120.2$ (d, $J=7.4 \mathrm{~Hz}), 123.8$, 130.1, 130.3, 131.9 (d, $J=8.3 \mathrm{~Hz}), 134.7$ (d, $J=3.3 \mathrm{~Hz}), 142.8$, 158.6 (d, $J=240.6 \mathrm{~Hz}), 159.5,159.7$. HPLC purity: $>99 \%$, ESIMS $m / z 347[\mathrm{M}+\mathrm{H}]^{+}$.

3,4,5-Trichloro- $N$-(6-fluorobenzo[ $[d]$ thiazol-2-yl)thiophene-2-carboxamide (2n) According to the same procedure used for $\mathbf{2 d}$, starting from 3,4,5-trichlorothiophene2-carboxylic acid $(232 \mathrm{mg}, 1.00 \mathrm{mmol})$ and 6-fluorobenzo[d]thiazol-2-amine (185 mg, $1.10 \mathrm{mmol}), 2 \mathrm{n}(305 \mathrm{mg}, 80 \%)$ was obtained as white powder. mp: $299-301{ }^{\circ} \mathrm{C}$. ${ }^{1} \mathrm{H}-\mathrm{NMR}$ (DMSO$\left.d_{6}\right) \delta: 7.31(1 \mathrm{H}, \mathrm{dt}, J=8.8,2.4 \mathrm{~Hz}), 7.55(1 \mathrm{H}, \mathrm{dd}, J=8.8,4.8 \mathrm{~Hz})$, $7.82(1 \mathrm{H}, \mathrm{dd}, J=8.8,2.4 \mathrm{~Hz}) .{ }^{13} \mathrm{C}-\mathrm{NMR}\left(\mathrm{DMSO}-d_{6}\right) \delta: 109.0$ (d, $J=27.2 \mathrm{~Hz}), 114.6$ (d, $J=24.7 \mathrm{~Hz}), 115.9$ (d, $J=9.1 \mathrm{~Hz}), 116.0$, 124.1, 125.0, 128.1, 129.1 (d, $J=9.0 \mathrm{~Hz}), 130.7,143.9,156.4$, 158.6 (d, $J=230.6 \mathrm{~Hz}$ ). HPLC purity: $>99 \%$, ESI-MS $\mathrm{m} / z 381$ $[\mathrm{M}+\mathrm{H}]^{+}$.

$N$-(6-Fluorobenzo[d]thiazol-2-yl)furan-2-carboxamide (2o) According to the same procedure used for 2a, starting from furan-2-carboxylic acid $(112 \mathrm{mg}, 1.00 \mathrm{mmol})$ and 6-fluorobenzo[d]thiazol-2-amine $\quad(186 \mathrm{mg}, \quad 1.11 \mathrm{mmol}), \quad \mathbf{2 0}$ (167 mg, 64\%) was obtained as white powder. ${ }^{1} \mathrm{H}-\mathrm{NMR}$ $\left(\mathrm{DMSO}_{6}\right) \delta: 6.78(1 \mathrm{H}, \mathrm{dd}, J=3.6,1.6 \mathrm{~Hz}), 7.32(1 \mathrm{H}, \mathrm{dt}$, $J=8.8,2.4 \mathrm{~Hz}), 7.75(1 \mathrm{H}, \mathrm{d}, J=3.6 \mathrm{~Hz}), 7.78(1 \mathrm{H}, \mathrm{dd}, J=8.8$, $4.8 \mathrm{~Hz}), 7.93(1 \mathrm{H}, \mathrm{dd}, J=8.8,2.4 \mathrm{~Hz}), 8.07(1 \mathrm{H}, \mathrm{d}, J=1.6 \mathrm{~Hz})$. ${ }^{13} \mathrm{C}-\mathrm{NMR}\left(\mathrm{DMSO}-d_{6}\right) \delta$ : $108.2(\mathrm{~d}, J=27.2 \mathrm{~Hz}), 112.4,114.3(\mathrm{~d}$, $J=24.0 \mathrm{~Hz}), 117.2,121.4(\mathrm{~d}, J=8.2 \mathrm{~Hz}), 132.7$ (d, $J=13.3 \mathrm{~Hz})$, $145.1(\mathrm{~d}, J=5.0 \mathrm{~Hz}), 145.4,147.7,156.4,158.2,158.8$ (d, $J=249.7 \mathrm{~Hz}$ ). HPLC purity: 98\%, ESI-MS $m / z 263[\mathrm{M}+\mathrm{H}]^{+}$.

5-Chloro- $\boldsymbol{N}$-(6-fluorobenzo[ $[\boldsymbol{d}]$ thiazol-2-yl)furan-2-carboxamide (2p) According to the same procedure used for 2a, starting from 5-chlorofuran-2-carboxylic acid (147 mg, $1.00 \mathrm{mmol})$ and 6-fluorobenzo[ $d]$ thiazol-2-amine $(185 \mathrm{mg}$, $1.10 \mathrm{mmol}), 2 \mathrm{p}(97 \mathrm{mg}, 33 \%)$ was obtained as white powder. ${ }^{1} \mathrm{H}-\mathrm{NMR}\left(\mathrm{DMSO}-d_{6}\right) \delta: 6.82-6.84(1 \mathrm{H}, \mathrm{m}), 7.32(1 \mathrm{H}$, $\mathrm{ddt}, J=8.8,1.6 \mathrm{~Hz}), 7.76-7.79(2 \mathrm{H}, \mathrm{m}), 7.93(1 \mathrm{H}, \mathrm{dt}, J=8.8$, $2.4 \mathrm{~Hz}$ ). ${ }^{13} \mathrm{C}-\mathrm{NMR}$ (DMSO- $d_{6}$ ) $\delta: 108.2(\mathrm{~d}, J=27.3 \mathrm{~Hz}), 109.9$, 114.3 (d, $J=24.8 \mathrm{~Hz}), 119.3,121.3$ (d, $J=9.5 \mathrm{~Hz}), 132.6,132.7$, 140.0, 145.1, 155.6, 158.3, 158.7 (d, $J=239.8 \mathrm{~Hz}$ ). HPLC purity: $>99 \%$, ESI-MS $m / z 297[\mathrm{M}+\mathrm{H}]^{+}$.

5-Bromo- $N$-(6-fluorobenzo[d]thiazol-2-yl)furan-2-carboxamide (2q) According to the same procedure used for 2a, starting from 5-bromofuran-2-carboxylic acid (191 mg, $1.00 \mathrm{mmol})$ and 6-fluorobenzo[ $d]$ thiazol-2-amine $(185 \mathrm{mg}$, $1.10 \mathrm{mmol}), \mathbf{2 q}(78 \mathrm{mg}, 23 \%)$ was obtained as beige powder.
${ }^{1} \mathrm{H}-\mathrm{NMR}\left(\mathrm{DMSO}-d_{6}\right) \delta: 6.92(1 \mathrm{H}, \mathrm{d}, J=4.0 \mathrm{~Hz}), 7.32(1 \mathrm{H}$, $\mathrm{dt}, J=8.8,2.4 \mathrm{~Hz}), 7.79-7.75(2 \mathrm{H}, \mathrm{m}), 7.93(1 \mathrm{H}, \mathrm{dd}, J=8.8$, $2.4 \mathrm{~Hz}$ ). ${ }^{13} \mathrm{C}-\mathrm{NMR}$ (DMSO- $\left.d_{6}\right) \delta$ : $108.2(\mathrm{~d}, J=27.3 \mathrm{~Hz}$ ), 114.4 (d, $J=24.8 \mathrm{~Hz}), 114.6,119.4,121.4(\mathrm{~d}, J=8.3 \mathrm{~Hz}), 127.8,132.7$ (d, $J=8.3 \mathrm{~Hz}), 145.4,147.3,155.5,158.2,158.7$ (d, $J=239.8 \mathrm{~Hz})$. HPLC purity: 97\%, ESI-MS $m / z 341[\mathrm{M}+\mathrm{H}]^{+}$.

$\mathrm{N}$-(6-Fluorobenzo $[\boldsymbol{d}]$ thiazol-2-yl)thiazole-2-carboxamide (2r) According to the same procedure used for $\mathbf{2 a}$, starting from thiazole-2-carboxylic acid $(129 \mathrm{mg}, 1.00 \mathrm{mmol})$ and 6-fluorobenzo[d]thiazol-2-amine $(186 \mathrm{mg}, 1.11 \mathrm{mmol})$, 2r $(46 \mathrm{mg}, 17 \%)$ was obtained as white powder. ${ }^{1} \mathrm{H}-\mathrm{NMR}$ $\left(\mathrm{DMSO}-d_{6}\right) \delta$ : $7.34(1 \mathrm{H}, \mathrm{dt}, J=8.8,2.4 \mathrm{~Hz}), 7.82(1 \mathrm{H}, \mathrm{dd}$, $J=8.8,4.8 \mathrm{~Hz}), 7.96(1 \mathrm{H}, \mathrm{dd}, J=8.8,2.4 \mathrm{~Hz}), 8.19(1 \mathrm{H}, \mathrm{d}$, $J=2.8 \mathrm{~Hz}), 8.25(1 \mathrm{H}, \mathrm{d}, J=2.8 \mathrm{~Hz}) .{ }^{13} \mathrm{C}-\mathrm{NMR}\left(\mathrm{DMSO}-d_{6}\right) \delta$ : $108.3(\mathrm{~d}, J=27.3 \mathrm{~Hz}), 114.5$ (d, $J=24.8 \mathrm{~Hz}), 121.6,127.8,132.7$ (d, $J=8.3 \mathrm{~Hz}), 132.9,144.7,157.9,158.9$ (d, $J=240.5 \mathrm{~Hz}), 159.3$, 160.9. HPLC purity: $>99 \%$, ESI-MS $m / z 280[\mathrm{M}+\mathrm{H}]^{+}$.

$N$-(6-Fluorobenzo[ $d]$ thiazol-2-yl)benzo[b]thiophene2-carboxamide (2s) According to the same procedure used for 2a, starting from benzo[b]thiophene-2-carboxylic acid $(179 \mathrm{mg}, \quad 1.00 \mathrm{mmol})$ and 6-fluorobenzo $[d]$ thiazol-2-amine (186 mg, $1.11 \mathrm{mmol}), 2 \mathrm{~s}$ (139 mg, 42\%) was obtained as white powder. mp: $235-236^{\circ} \mathrm{C} .{ }^{1} \mathrm{H}-\mathrm{NMR}\left(\mathrm{DMSO}-d_{6}\right) \delta: 7.34(1 \mathrm{H}, \mathrm{dt}$, $J=8.8,2.4 \mathrm{~Hz}), 7.48-7.57(2 \mathrm{H}, \mathrm{m}), 7.81(1 \mathrm{H}, \mathrm{dd}, J=8.8,4.8 \mathrm{~Hz})$, $7.95(1 \mathrm{H}, \mathrm{dd}, J=8.8,2.4 \mathrm{~Hz}), 8.03(1 \mathrm{H}, \mathrm{d}, J=7.2 \mathrm{~Hz}), 8.10(1 \mathrm{H}$, d, $J=8.8 \mathrm{~Hz}), 8.64(1 \mathrm{H}, \mathrm{s}) .{ }^{13} \mathrm{C}-\mathrm{NMR}\left(\mathrm{DMSO}-d_{6}\right) \delta: 108.3$ (d, $J=26.4 \mathrm{~Hz}), 114.4(\mathrm{~d}, J=24.8 \mathrm{~Hz}), 121.3(\mathrm{~d}, J=10.7 \mathrm{~Hz})$, $122.9,125.3,126.0,127.2,128.5,132.6$ (d, $J=9.1 \mathrm{~Hz}), 137.1$ (d, $J=4.9 \mathrm{~Hz}), 139.0,141.1,144.9,158.7$ (d, $J=239.8 \mathrm{~Hz}), 158.8$, 161.6. HPLC purity: $>99 \%$, ESI-MS $m / z 329[\mathrm{M}+\mathrm{H}]^{+}$.

2-Bromo- $N$-(6-fluorobenzo[ $d]$ thiazol-2-yl)thiophene3-carboxamide (2t) A mixture of 2-bromothiophene-3-carboxylic acid $(207 \mathrm{mg}, 1.10 \mathrm{mmol})$, 6-fluorobenzo[d]thiazol-2amine $(186 \mathrm{mg}, 1.11 \mathrm{mmol})$, DMAP $(183 \mathrm{mg}, 1.50 \mathrm{mmol})$ and $\mathrm{EDC} \cdot \mathrm{HCl}(288 \mathrm{mg}, 1.50 \mathrm{mmol})$ in $\mathrm{CH}_{2} \mathrm{Cl}_{2}(2 \mathrm{~mL})$ was stirred overnight at $\mathrm{rt}$. The reaction mixture was diluted with $\mathrm{CH}_{2} \mathrm{Cl}_{2}$ and washed with $2 \mathrm{~N} \mathrm{HCl}, \mathrm{H}_{2} \mathrm{O}$, and brine. The organic layer was dried over $\mathrm{MgSO}_{4}$ and concentrated. The residue was washed several times with $\mathrm{CH}_{2} \mathrm{Cl}_{2}$ and $\mathrm{MeOH}$ to give $\mathbf{2 t}$ (72 mg, 20\%) as white powder. ${ }^{1} \mathrm{H}-\mathrm{NMR}\left(\mathrm{DMSO}-d_{6}\right) \delta: 7.33$ $(1 \mathrm{H}, \mathrm{ddt}, J=8.8,2.4,0.8 \mathrm{~Hz}), 7.61(1 \mathrm{H}, \mathrm{dd}, J=6.0,1.2 \mathrm{~Hz})$, $7.75(1 \mathrm{H}, \mathrm{dd}, J=6.0,1.2 \mathrm{~Hz}), 7.80(1 \mathrm{H}, \mathrm{dd}, J=8.8,4.8 \mathrm{~Hz}), 7.94$ $(1 \mathrm{H}, \mathrm{dd}, J=8.8,2.4 \mathrm{~Hz}) .{ }^{13} \mathrm{C}-\mathrm{NMR}\left(\mathrm{DMSO}-d_{6}\right) \delta: 108.2(\mathrm{~d}$, $J=27.2 \mathrm{~Hz}), 114.4$ (d, $J=24.8 \mathrm{~Hz}), 117.5,121.6,128.0,128.1$, 132.7 (d, $J=10.7 \mathrm{~Hz}), 133.0,145.1$ (d, $J=10.7 \mathrm{~Hz}), 158.2,158.8$ (d, $J=239.8 \mathrm{~Hz}), 161.3$. HPLC purity: $>99 \%$, ESI-MS $\mathrm{m} / z 357$ $[\mathrm{M}+\mathrm{H}]^{+}$.

4-Bromo- $N$-(6-fluorobenzo $[d]$ thiazol-2-yl)thiophene3-carboxamide (2u) According to the same procedure used for $\mathbf{2 t}$, starting from 4-bromothiophene-3-carboxylic acid $(207 \mathrm{mg}, \quad 1.00 \mathrm{mmol})$ and 6-fluorobenzo $[d]$ thiazol-2-amine (185 mg, $1.10 \mathrm{mmol}), 2 \mathbf{u}(134 \mathrm{mg}, 37 \%)$ was obtained as white powder. ${ }^{1} \mathrm{H}-\mathrm{NMR}\left(\mathrm{DMSO}-d_{6}\right) \delta: 7.33(1 \mathrm{H}, \mathrm{dt}, J=8.8,2.4 \mathrm{~Hz})$, $7.80(1 \mathrm{H}, \mathrm{dd}, J=8.8,4.8 \mathrm{~Hz}), 7.86(1 \mathrm{H}, \mathrm{dd}, J=3.6,1.2 \mathrm{~Hz})$, $7.94(1 \mathrm{H}, \mathrm{dd}, J=8.8,2.4 \mathrm{~Hz}), 8.48(1 \mathrm{H}, \mathrm{dd}, J=3.6,1.2 \mathrm{~Hz})$. ${ }^{13} \mathrm{C}-\mathrm{NMR}\left(\mathrm{DMSO}-d_{6}\right) \delta$ : $108.2(\mathrm{~d}, J=26.4 \mathrm{~Hz}), 109.0,114.3(\mathrm{~d}$, $J=24.8 \mathrm{~Hz}), 121.6(\mathrm{~d}, J=9.1 \mathrm{~Hz}), 126.5,132.7$ (d, $J=10.7 \mathrm{~Hz})$, 132.8, 132.9, 145.1, 158.2, 158.7 (d, $J=239.7 \mathrm{~Hz}), 161.2$. HPLC purity: $>99 \%$, ESI-MS m/z $357[\mathrm{M}+\mathrm{H}]^{+}$.

5-Bromo- $N$-(6-fluorobenzo[ $d]$ thiazol-2-yl)thiophene3-carboxamide (2v) According to the same procedure used 
for 2d, starting from 5-bromothiophene-3-carboxylic acid $(207 \mathrm{mg}, \quad 1.00 \mathrm{mmol})$ and 6-fluorobenzo[d]thiazol-2-amine (186 mg, $1.11 \mathrm{mmol}), \mathbf{2 v}(278 \mathrm{mg}, 78 \%$ ) was obtained as white powder. ${ }^{1} \mathrm{H}-\mathrm{NMR}\left(\mathrm{DMSO}-d_{6}\right) \delta: 7.32(1 \mathrm{H}, \mathrm{dt}, J=8.8,2.4 \mathrm{~Hz})$, $7.79(1 \mathrm{H}, \mathrm{dd}, J=8.8,4.8 \mathrm{~Hz}), 7.87(1 \mathrm{~h}, \mathrm{~d}, J=1.6 \mathrm{~Hz}), 7.93(1 \mathrm{H}$, dd, $J=8.8,2.4 \mathrm{~Hz}), 8.64(1 \mathrm{H}, \mathrm{d}, J=1.6 \mathrm{~Hz}) .{ }^{13} \mathrm{C}-\mathrm{NMR}$ (DMSO$\left.d_{6}\right) \delta: 108.2(\mathrm{~d}, J=27.2 \mathrm{~Hz}), 112.8,114.3(\mathrm{~d}, J=24.8 \mathrm{~Hz}), 121.5$ (d, $J=9.1 \mathrm{~Hz}), 129.8,132.8$ (d, $J=11.5 \mathrm{~Hz}), 134.6,135.1,145.2$, 158.4, 158.7 (d, $J=239.8 \mathrm{~Hz}), 159.9$. HPLC purity: $>99 \%$, ESIMS $m / z 357[\mathrm{M}+\mathrm{H}]^{+}$.

2,5-Dibromo- $N$-(6-fluorobenzo[d] thiazol-2-yl)thiophene3-carboxamide (2w) According to the same procedure used for $\mathbf{2 d}$, starting from 2,5-dibromothiophene-3-carboxylic acid $(286 \mathrm{mg}, \quad 1.00 \mathrm{mmol})$ and 6-fluorobenzo[d]thiazol-2-amine (185 mg, $1.10 \mathrm{mmol}), \mathbf{2 w}(313 \mathrm{mg}, 72 \%)$ was obtained as white powder. ${ }^{1} \mathrm{H}-\mathrm{NMR}\left(\mathrm{DMSO}-d_{6}\right) \delta: 7.33(1 \mathrm{H}, \mathrm{dt}, J=8.8$, $2.4 \mathrm{~Hz}), 7.78-7.82(2 \mathrm{H}, \mathrm{m}), 7.94(1 \mathrm{H}, \mathrm{dd}, J=8.8,2.4 \mathrm{~Hz})$. ${ }^{13} \mathrm{C}-\mathrm{NMR}\left(\mathrm{DMSO}-d_{6}\right) \quad \delta$ : $108.2(\mathrm{~d}, J=27.2 \mathrm{~Hz}), 111.3,114.4$ (d, $J=24.8 \mathrm{~Hz}), 117.0,121.6(\mathrm{~d}, J=9.8 \mathrm{~Hz}), 131.1,132.7$ (d, $J=11.5 \mathrm{~Hz}$ ), 134.2, 144.7, 158.1, 158.8 (d, $J=239.7 \mathrm{~Hz}), 160.2$. HPLC purity: $>99 \%$, ESI-MS $m / z 435[\mathrm{M}+\mathrm{H}]^{+}$.

$N$-(Benzo[d]thiazol-2-yl)-5-bromothiophene-2-carboxamide (3a) A mixture of 5-bromothiophene-2-carboxylic acid $(207 \mathrm{mg}, 1.00 \mathrm{mmol})$, benzo[d]thiazol-2-amine $(166 \mathrm{mg}$, $1.10 \mathrm{mmol})$, DMAP $(183 \mathrm{mg}, 1.50 \mathrm{mmol})$ and $\mathrm{EDC} \cdot \mathrm{HCl}$ (288 mg, $1.50 \mathrm{mmol})$ in $\mathrm{CH}_{2} \mathrm{Cl}_{2}(2 \mathrm{~mL})$ was stirred overnight at rt. $\mathrm{CH}_{2} \mathrm{Cl}_{2}$ and $2 \mathrm{~N} \mathrm{HCl}$ were added, the precipitate was filtered and washed several times with $\mathrm{CH}_{2} \mathrm{Cl}_{2}$ and $\mathrm{MeOH}$. The residue was purified by $\mathrm{NH}$-silica-gel column chromatography (eluent: $\mathrm{CH}_{2} \mathrm{Cl}_{2} / \mathrm{MeOH}=4: 1$ to $\left.10: 3\right)$ to give 3a $(106 \mathrm{mg}, 31 \%$ ) as white powder. ${ }^{1} \mathrm{H}-\mathrm{NMR}\left(\mathrm{DMSO}-d_{6}\right) \delta: 7.34(1 \mathrm{H}, \mathrm{dt}, J=8.4$, $1.6 \mathrm{~Hz}), 7.43(1 \mathrm{H}, \mathrm{d}, J=3.6 \mathrm{~Hz}), 7.47(1 \mathrm{H}, \mathrm{dt}, J=8.4,1.6 \mathrm{~Hz})$, $7.74(1 \mathrm{H}, \mathrm{d}, J=8.0 \mathrm{~Hz}), 8.00(1 \mathrm{H}, \mathrm{d}, J=8.0 \mathrm{~Hz}), 8.06(1 \mathrm{H}, \mathrm{s})$. ${ }^{13} \mathrm{C}-\mathrm{NMR}$ (DMSO- $d_{6}$ ) $\delta: 119.9,121.9,123.7,126.4,130.8$, $131.2,132.1,132.2,139.5,152.3,160.3,160.7$. HPLC purity: $>99 \%$, ESI-MS $m / z 339[\mathrm{M}+\mathrm{H}]^{+}$.

5-Bromo- $N$-(6-chlorobenzo[ $d]$ thiazol-2-yl)thiophene2-carboxamide (3b) According to the same procedure used for 1, starting from 5-bromothiophene-2-carboxylic acid $(205 \mathrm{mg}, \quad 0.99 \mathrm{mmol})$ and 6-chlorobenzo[d]thiazol-2-amine (202 mg, $1.10 \mathrm{mmol})$, 3b (143 mg, 38\%) was obtained as light yellow powder. mp: $254-256^{\circ} \mathrm{C} .{ }^{1} \mathrm{H}-\mathrm{NMR}$ (DMSO- $\left.d_{6}\right) \delta: 7.43$ $(1 \mathrm{H}, \mathrm{d}, J=3.6 \mathrm{~Hz}), 7.48(1 \mathrm{H}, \mathrm{dd}, J=8.4,1.6 \mathrm{~Hz}), 7.74(1 \mathrm{H}, \mathrm{d}$, $J=8.4 \mathrm{~Hz}), 8.09(1 \mathrm{H}, \mathrm{d}, J=3.6 \mathrm{~Hz}), 8.15(1 \mathrm{H}, \mathrm{d}, J=1.6 \mathrm{~Hz})$. ${ }^{13} \mathrm{C}-\mathrm{NMR}$ (DMSO- $d_{6}$ ) $\delta: 120.3,121.1,121.5,126.6,127.8$, $132.3,132.4,132.9,138.9,150.4,158.4,159.9$. HPLC purity: $>99 \%$, ESI-MS $m / z 373[\mathrm{M}+\mathrm{H}]^{+}$.

5-Bromo- $N$-(6-bromobenzo $[d]$ thiazol-2-yl)thiophene2-carboxamide (3c) According to the same procedure used for 2a, starting from 5-bromothiophene-2-carboxylic acid (209 $\mathrm{mg}, \quad 1.01 \mathrm{mmol})$ and 6-bromobenzo[d]thiazol-2-amine (256 mg, $1.10 \mathrm{mmol}), 3 c(40 \mathrm{mg}, 10 \%)$ was obtained as white powder. ${ }^{1} \mathrm{H}-\mathrm{NMR}\left(\mathrm{DMSO}-d_{6}\right) \delta: 7.43(1 \mathrm{H}, \mathrm{d}, J=3.6 \mathrm{~Hz}), 7.60$ $(1 \mathrm{H}, \mathrm{dd}, J=8.4,1.6 \mathrm{~Hz}), 7.69(1 \mathrm{H}, \mathrm{d}, J=8.0 \mathrm{~Hz}), 8.09(1 \mathrm{H}, \mathrm{s})$, $8.28(1 \mathrm{H}, \mathrm{d}, J=1.6 \mathrm{~Hz}) .{ }^{13} \mathrm{C}-\mathrm{NMR}\left(\mathrm{DMSO}-d_{6}\right) \delta: 115.7,120.3$, $121.6,121.8,124.3,129.3,129.6,132.3,133.4,138.9,147.8$, 159.8. HPLC purity: 97\%, ESI-MS $m / z 417[\mathrm{M}+\mathrm{H}]^{+}$.

5-Bromo- $N$-(5-fluorobenzo $[d]$ thiazol-2-yl)thiophene2-carboxamide (3d) According to the same procedure used for 2a, starting from 5-bromothiophene-2-carboxylic acid $(206 \mathrm{mg}, \quad 1.00 \mathrm{mmol})$ and 5-fluorobenzo[d]thiazol-2-amine
(191 mg, $1.10 \mathrm{mmol}), 3 d$ (30 mg, 8\%) was obtained as white powder. ${ }^{1} \mathrm{H}-\mathrm{NMR}$ (DMSO- $\left.d_{6}\right) \delta: 7.23(1 \mathrm{H}, \mathrm{dt}, J=8.8,2.4 \mathrm{~Hz})$, $7.44(1 \mathrm{H}, \mathrm{d}, J=3.6 \mathrm{~Hz}), 7.59(1 \mathrm{H}, \mathrm{d}, J=9.6 \mathrm{~Hz}), 8.04(1 \mathrm{H}, \mathrm{dd}$, $J=8.8,5.6 \mathrm{~Hz}), 8.11(1 \mathrm{H}, \mathrm{s}) .{ }^{13} \mathrm{C}-\mathrm{NMR}\left(\mathrm{DMSO}-d_{6}\right) \delta: 106.3$, $111.8(\mathrm{~d}, J=24.0 \mathrm{~Hz}), 120.3,123.2(\mathrm{~d}, J=9.9 \mathrm{~Hz}), 127.1$ (d, $J=4.1 \mathrm{~Hz}), 132.3,132.6,138.9$ (d, $J=6.6 \mathrm{~Hz}), 148.7,159.4$, 161.0, 161.4 (d, $J=239.7 \mathrm{~Hz}$ ). HPLC purity: $>99 \%$, ESI-MS $m / z$ $357[\mathrm{M}+\mathrm{H}]^{+}$.

5-Bromo- $N$-(5-chlorobenzo $[d]$ thiazol-2-yl)thiophene2-carboxamide (3e) According to the same procedure used for 2d, starting from 5-bromothiophene-2-carboxylic acid $(207 \mathrm{mg}, \quad 1.00 \mathrm{mmol})$ and 5-chlorobenzo[d]thiazol-2-amine (203 mg, $1.10 \mathrm{mmol}), 3$ e $(214 \mathrm{mg}, 57 \%)$ was obtained as white powder. ${ }^{1} \mathrm{H}-\mathrm{NMR}\left(\mathrm{DMSO}-d_{6}\right) \delta: 7.37(1 \mathrm{H}, \mathrm{dd}, J=8.8,1.6 \mathrm{~Hz})$, $7.43(1 \mathrm{H}, \mathrm{d}, J=3.6 \mathrm{~Hz}), 7.81(1 \mathrm{H}, \mathrm{s}), 8.04(1 \mathrm{H}, \mathrm{d}, J=8.8 \mathrm{~Hz})$, $8.10(1 \mathrm{H}, \mathrm{s}) .{ }^{13} \mathrm{C}-\mathrm{NMR}$ (DMSO- $\left.d_{6}\right) \quad \delta: 119.5,120.3,123.4$, $123.7,130.1,130.9,132.2,132.3,138.8,149.0,159.8,160.8$. HPLC purity: $>99 \%$, ESI-MS $m / z 373[\mathrm{M}+\mathrm{H}]^{+}$.

5-Bromo- $N$-(5-bromobenzo $[d]$ thiazol-2-yl)thiophene2-carboxamide (3f) According to the same procedure used for 2f, starting from 5-bromothiophene-2-carboxylic acid (207 mg, $\quad 1.00 \mathrm{mmol})$ and 5-bromobenzo[d]thiazol-2-amine (252 mg, $1.10 \mathrm{mmol}), 3 f(220 \mathrm{mg}, 53 \%)$ was obtained as white powder. ${ }^{1} \mathrm{H}-\mathrm{NMR}$ (DMSO- $\left.d_{6}\right) \quad \delta: 7.43(1 \mathrm{H}, \mathrm{d}, J=3.6 \mathrm{~Hz})$, $7.49(1 \mathrm{H}, \mathrm{ddd}, J=8.4,1.6,0.8 \mathrm{~Hz}), 7.95(1 \mathrm{H}, \mathrm{s}), 7.98(1 \mathrm{H}, \mathrm{d}$, $J=8.4 \mathrm{~Hz}), 8.10(1 \mathrm{H}, \mathrm{d}, J=3.6 \mathrm{~Hz}) .{ }^{13} \mathrm{C}-\mathrm{NMR}$ (DMSO- $\left.d_{6}\right) \delta$ : $119.0,120.4,122.4,123.7,126.4,130.5,132.3,132.4,138.8$, 149.4, 159.9, 160.3. HPLC purity: >99\%, ESI-MS $\mathrm{m} / \mathrm{z} 417$ $[\mathrm{M}+\mathrm{H}]^{+}$.

5-Bromo- $N$-(4-fluorobenzo $[d]$ thiazol-2-yl)thiophene2-carboxamide (3g) According to the same procedure used for 2a, starting from 5-bromothiophene-2-carboxylic acid $(212 \mathrm{mg}, \quad 1.02 \mathrm{mmol})$ and 4-fluorobenzo $[d]$ thiazol-2-amine (186 mg, $1.11 \mathrm{mmol}), 3 \mathrm{~g}(52.4 \mathrm{mg}, 15 \%)$ was obtained as white powder. ${ }^{1} \mathrm{H}-\mathrm{NMR}\left(\mathrm{DMSO}-d_{6}\right) \delta: 7.39(1 \mathrm{H}, \mathrm{d}, J=3.6 \mathrm{~Hz}), 7.53$ $(1 \mathrm{H}, \mathrm{m}), 7.73(1 \mathrm{H}, \mathrm{dd}, J=8.4,1.6 \mathrm{~Hz}), 7.78(1 \mathrm{H}, \mathrm{t}, J=8.4 \mathrm{~Hz})$, $7.88(1 \mathrm{H}, \mathrm{d}, J=3.6 \mathrm{~Hz}), 10.42(1 \mathrm{H}, \mathrm{s}) .{ }^{13} \mathrm{C}-\mathrm{NMR}$ (DMSO- $\left.d_{6}\right)$ $\delta$ : $111.3,118.3,118.5$ (d, $J=2.5 \mathrm{~Hz}), 122.2$ (d, $J=8.3 \mathrm{~Hz}), 126.6$ (d, $J=12.4 \mathrm{~Hz}), 126.9$ (d, $J=4.2 \mathrm{~Hz}), 128.0,130.8,131.9,140.3$, $155.1(\mathrm{~d}, J=252.1 \mathrm{~Hz}), 158.9$. HPLC purity: $>99 \%$, ESI-MS $m / z 357[\mathrm{M}+\mathrm{H}]^{+}$.

5-Bromo- $N$-(4-chlorobenzo $[d]$ thiazol-2-yl)thiophene2-carboxamide (3h) According to the same procedure used for 2d, starting from 5-bromothiophene-2-carboxylic acid $(207 \mathrm{mg}, \quad 1.00 \mathrm{mmol})$ and 4-chlorobenzo $[d]$ thiazol-2-amine (204 mg, $1.10 \mathrm{mmol}), \mathbf{3 h}$ (132 mg, 35\%) was obtained as white powder. ${ }^{1} \mathrm{H}-\mathrm{NMR}$ (DMSO- $\left.d_{6}\right) \delta: 7.33(1 \mathrm{H}, \mathrm{dt}, J=8.4,0.4 \mathrm{~Hz})$, $7.44(1 \mathrm{H}, \mathrm{dd}, J=4.0,0.4 \mathrm{~Hz}), 7.55(1 \mathrm{H}, \mathrm{d}, J=8.0 \mathrm{~Hz}), 8.00(1 \mathrm{H}$, d, $J=8.0 \mathrm{~Hz}), 8.21(1 \mathrm{H}, \mathrm{d}, J=4.0 \mathrm{~Hz}) .{ }^{13} \mathrm{C}-\mathrm{NMR}\left(\mathrm{DMSO}-d_{6}\right)$ $\delta$ : 120.6, 120.8, 124.4, 124.6, 129.3, 132.4, 132.6, 133.3, 138.4, 145.4, 159.3, 159.4. HPLC purity: >99\%, ESI-MS $m / z 373$ $[\mathrm{M}+\mathrm{H}]^{+}$.

5-Bromo- $N$-(4-bromobenzo $[d]$ thiazol-2-yl)thiophene2-carboxamide (3i) According to the same procedure used for 2t, starting from 5-bromothiophene-2-carboxylic acid $(207 \mathrm{mg}, \quad 1.00 \mathrm{mmol})$ and 4-bromobenzo[d]thiazol-2-amine (253 mg, $1.10 \mathrm{mmol}), 3 \mathbf{i}(257 \mathrm{mg}, 61 \%)$ was obtained as white powder. ${ }^{1} \mathrm{H}-\mathrm{NMR}$ (DMSO- $\left.d_{6}\right) \quad \delta$ : $7.26(1 \mathrm{H}, \mathrm{t}, J=8.4 \mathrm{~Hz})$, $7.44(1 \mathrm{H}, \mathrm{d}, J=4.0 \mathrm{~Hz}), 7.70(1 \mathrm{H}, \mathrm{d}, J=8.0 \mathrm{~Hz}), 8.03(1 \mathrm{H}, \mathrm{d}$, $J=8.0 \mathrm{~Hz}), 8.22(1 \mathrm{H}, \mathrm{d}, J=4.0 \mathrm{~Hz}) .{ }^{13} \mathrm{C}-\mathrm{NMR}\left(\mathrm{DMSO}-d_{6}\right) \delta$ : $113.6,120.6,121.3,125.0,129.4,132.4,132.6$, 132.7, 138.4, 
146.7, 159.1, 159.5. HPLC purity: >99\%, ESI-MS $\mathrm{m} / \mathrm{z} 417$ $[\mathrm{M}+\mathrm{H}]^{+}$.

5-Bromo- $N$-(4,6-difluorobenzo $[d]$ thiazol-2-yl)thiophene2-carboxamide (3j) According to the same procedure used for 2a, starting from 5-bromothiophene-2-carboxylic acid $(212 \mathrm{mg}, 1.02 \mathrm{mmol})$ and 4,6-difluorobenzo[d] thiazol-2-amine (205 mg, $1.11 \mathrm{mmol}), 3 \mathbf{j}$ (95 mg, 25\%) was obtained as white powder. mp: $252-254^{\circ} \mathrm{C} .{ }^{1} \mathrm{H}-\mathrm{NMR}\left(\mathrm{DMSO}-d_{6}\right) \delta: 7.31(1 \mathrm{H}, \mathrm{dt}$, $J=10.4,2.4 \mathrm{~Hz}), 7.40(1 \mathrm{H}, \mathrm{d}, J=4.0 \mathrm{~Hz}), 7.76(1 \mathrm{H}, \mathrm{dd}, J=8.4$, $1.6 \mathrm{~Hz}), 8.11(1 \mathrm{H}, \mathrm{d}, J=4.0 \mathrm{~Hz}) \cdot{ }^{13} \mathrm{C}-\mathrm{NMR}\left(\mathrm{DMSO}-d_{6}\right) \delta: 101.6$ (dd, $J=28.9,22.4 \mathrm{~Hz}), 104.0$ (dd, $J=26.5,4.2 \mathrm{~Hz}), 120.0$ (d, $J=5.8 \mathrm{~Hz}), 131.9,132.2,133.6$ (d, $J=8.2 \mathrm{~Hz}), 134.7$ (dd, $J=11.9$, $6.6 \mathrm{~Hz}), 138.1(\mathrm{~d}, J=9.9 \mathrm{~Hz}), 153.1(\mathrm{dd}, J=254.2,12.8 \mathrm{~Hz})$, $157.9(\mathrm{dd}, J=243.2,10.7 \mathrm{~Hz}), 158.4,158.5$. HPLC purity: $>99 \%$, ESI-MS $m / z 375[\mathrm{M}+\mathrm{H}]^{+}$.

5-Bromo- $N$-(4,6-dichlorobenzo[ $d]$ thiazol-2-yl)thiophene2-carboxamide (3k) According to the same procedure used for 2d, starting from 5-bromothiophene-2-carboxylic acid $(207 \mathrm{mg}, 1.00 \mathrm{mmol})$ and 4,6-dichlorobenzo[ $d]$ thiazol-2amine (241 mg, $1.10 \mathrm{mmol}), 3 \mathbf{k}(276 \mathrm{mg}, 68 \%)$ was obtained as light yellow powder. ${ }^{1} \mathrm{H}-\mathrm{NMR}\left(\mathrm{DMSO}-d_{6}\right) \delta: 7.44(1 \mathrm{H}$, d, $J=4.0 \mathrm{~Hz}), 7.67(1 \mathrm{H}, \mathrm{d}, J=1.6 \mathrm{~Hz}), 8.16(1 \mathrm{H}, \mathrm{d}, J=1.6 \mathrm{~Hz})$, $8.19(1 \mathrm{H}, \mathrm{d}, J=4.0 \mathrm{~Hz}) .{ }^{13} \mathrm{C}-\mathrm{NMR}$ (DMSO- $\left.d_{6}\right) \delta: 120.6,120.8$, $125.0,126.1,127.7,132.4,132.7,134.3,138.3,144.6,159.6$, 160.2. HPLC purity: $>99 \%$, ESI-MS $m / z 407[\mathrm{M}+\mathrm{H}]^{+}$.

5-Bromo- $N$-(4-bromo-6-fluorobenzo[d]thiazol-2-yl)thiophene-2-carboxamide (3I) According to the same procedure used for 3a, starting from 5-bromothiophene-2-carboxylic acid (207 mg, $1.00 \mathrm{mmol})$ and 4-bromo-6-fluoro benzo[d]thiazol-2amine (272 mg, $1.10 \mathrm{mmol}), 31$ (303 mg, 69\%) was obtained as light yellow powder. mp: $231^{\circ} \mathrm{C}$. ${ }^{1} \mathrm{H}-\mathrm{NMR}\left(\mathrm{DMSO}-d_{6}\right) \delta: 7.44$ $(1 \mathrm{H}, \mathrm{d}, J=4.0 \mathrm{~Hz}), 7.69(1 \mathrm{H}, \mathrm{dd}, J=8.8,2.4 \mathrm{~Hz}), 8.00(1 \mathrm{H}, \mathrm{dd}$, $J=8.8,2.4 \mathrm{~Hz}), 8.20(1 \mathrm{H}, \mathrm{d}, J=4.0 \mathrm{~Hz}), 8.32(1 \mathrm{H}, \mathrm{s}) .{ }^{13} \mathrm{C}-\mathrm{NMR}$ $\left(\mathrm{DMSO}_{6}\right) \delta: 107.9(\mathrm{~d}, J=26.4 \mathrm{~Hz}), 113.5(\mathrm{~d}, J=10.7 \mathrm{~Hz})$, 117.7 (d, $J=28.1 \mathrm{~Hz}), 120.6,132.3,132.6,133.2$ (d, $J=11.5 \mathrm{~Hz})$, $138.3,143.8,158.0$ (d, $J=243.9 \mathrm{~Hz}), 159.0,159.5$. HPLC purity: $>99 \%$, ESI-MS $m / z 435[\mathrm{M}+\mathrm{H}]^{+}$.

5-Bromo- $N$-(5,6-difluorobenzo $[d]$ thiazol-2-yl)thiophene2-carboxamide $(\mathbf{3 m})$ According to the same procedure used for 2d, starting from 5-bromothiophene-2-carboxylic acid $(207 \mathrm{mg}, 1.02 \mathrm{mmol})$ and 5,6-difluorobenzo[d]thiazol-2-amine (205 mg, $1.11 \mathrm{mmol}), 3 \mathrm{~m}(210 \mathrm{mg}, 56 \%)$ was obtained as white powder. ${ }^{1} \mathrm{H}-\mathrm{NMR}$ (DMSO- $\left.d_{6}\right) \delta: 7.43(1 \mathrm{H}, \mathrm{dd}, J=4.0,1.6 \mathrm{~Hz})$, $7.84(1 \mathrm{H}, \mathrm{dd}, J=11.2,7.2 \mathrm{~Hz}), 8.11(1 \mathrm{H}, \mathrm{d}, J=4.0 \mathrm{~Hz}), 8.16(1 \mathrm{H}$, t, $J=8.0 \mathrm{~Hz}$ ). ${ }^{13} \mathrm{C}-\mathrm{NMR}$ (DMSO- $\left.d_{6}\right) \delta: 108.3(\mathrm{~d}, J=13.3 \mathrm{~Hz}$ ), 110.0 (dd, $J=23.0,5.8 \mathrm{~Hz}$ ), 120.5, 127.2 (d, $J=6.6 \mathrm{~Hz}), 132.2$, 132.3, 132.4, 138.5, 147.0 (dd, $J=242.7,14.5 \mathrm{~Hz}$ ), 149.2 (dd, $J=242.7,14.5 \mathrm{~Hz}), 159.4,160.3$. HPLC purity: $>99 \%$, ESI-MS $\mathrm{m} / \mathrm{z} 375[\mathrm{M}+\mathrm{H}]^{+}$.

5-Bromo- $N$-(6-methylbenzo $[d]$ thiazol-2-yl)thiophene2-carboxamide (3n) According to the same procedure used for 3a, starting from 5-bromothiophene-2-carboxylic acid $(207 \mathrm{mg}, \quad 1.00 \mathrm{mmol})$ and 6-methylbenzo[d]thiazol-2-amine (180 mg, $1.10 \mathrm{mmol}), 3 \mathbf{n}(92 \mathrm{mg}, 26 \%)$ was obtained as white powder. ${ }^{1} \mathrm{H}-\mathrm{NMR}$ (DMSO- $\left.d_{6}\right) \delta: 2.42(3 \mathrm{H}, \mathrm{s}), 7.28(1 \mathrm{H}, \mathrm{d}$, $J=8.0 \mathrm{~Hz}), 7.41(1 \mathrm{H}, \mathrm{d}, J=4.0 \mathrm{~Hz}), 7.62(1 \mathrm{H}, \mathrm{d}, J=8.0 \mathrm{~Hz})$, $7.78(1 \mathrm{H}, \mathrm{s}), 8.04(1 \mathrm{H}, \mathrm{s}) .{ }^{13} \mathrm{C}-\mathrm{NMR}$ (DMSO- $\left.d_{6}\right) \delta: 21.0,119.3$, $119.7,121.5,127.6,131.1,131.9,132.2,133.2,139.6,139.7$, 159.4, 162.6. HPLC purity: $>99 \%$, ESI-MS $m / z 353[\mathrm{M}+\mathrm{H}]^{+}$.

5-Bromo- $N$-(4-methylbenzo $[d]$ thiazol-2-yl)thiophene2-carboxamide (3o) According to the same procedure used for 2a, starting from 5-bromothiophene-2-carboxylic acid $(207 \mathrm{mg}, \quad 1.00 \mathrm{mmol})$ and 4-methylbenzo[d]thiazol-2-amine (181 mg, $1.10 \mathrm{mmol}), 30(159 \mathrm{mg}, 45 \%)$ was obtained as light yellow powder. ${ }^{1} \mathrm{H}-\mathrm{NMR}\left(\mathrm{DMSO}-d_{6}\right) \delta$ : $2.62(3 \mathrm{H}, \mathrm{s}), 7.21-7.29$ $(2 \mathrm{H}, \mathrm{m}), 7.43(1 \mathrm{H}, \mathrm{d}, J=4.0 \mathrm{~Hz}), 7.81(1 \mathrm{H}, \mathrm{d}, J=8.0 \mathrm{~Hz}), 8.17$ $(1 \mathrm{H}, \mathrm{s}) .{ }^{13} \mathrm{C}-\mathrm{NMR}$ (DMSO- $\left.d_{6}\right) \quad \delta: 18.1,119.1,120.2,123.7$, $126.8,129.9,131.3,132.1,132.3,138.8,147.7,157.3,159.2$. HPLC purity: $>99 \%$, ESI-MS $m / z 353[\mathrm{M}+\mathrm{H}]^{+}$.

5-Bromo- $N$-(5,6-dimethylbenzo $[d]$ thiazol-2-yl)thiophene2-carboxamide (3p) According to the same procedure used for 3a, starting from 5-bromothiophene-2-carboxylic acid $(207 \mathrm{mg}, 1.00 \mathrm{mmol})$ and 5,6-dimethylbenzo[d]thiazol-2-amine (196 mg, $1.10 \mathrm{mmol}), 3 p$ (121 mg, 33\%) was obtained as beige powder. ${ }^{1} \mathrm{H}-\mathrm{NMR}$ (DMSO- $\left.d_{6}\right) \delta: 2.32(3 \mathrm{H}, \mathrm{s}), 2.33(3 \mathrm{H}, \mathrm{s})$, $7.41(1 \mathrm{H}, \mathrm{d}, J=4.0 \mathrm{~Hz}), 7.52(1 \mathrm{H}, \mathrm{s}), 7.72(1 \mathrm{H}, \mathrm{s}), 8.02(1 \mathrm{H}, \mathrm{s})$. ${ }^{13} \mathrm{C}-\mathrm{NMR}$ (DMSO- $d_{6}$ ) $\delta: 19.5,19.7,119.6,121.7,128.0,128.2$, $131.8,132.2$, 132.6, 135.1, 139.2, 139.7, 159.5, 160.2. HPLC purity: $>99 \%$, ESI-MS $m / z 367[\mathrm{M}+\mathrm{H}]^{+}$.

5-Bromo- $N$-(6-methoxybenzo $[d]$ thiazol-2-yl)thiophene2-carboxamide (3q) According to the same procedure used for 1, starting from 5-bromothiophene-2-carboxylic acid (208 $\mathrm{mg}, 1.01 \mathrm{mmol})$ and 6-methoxylbenzo[d]thiazol-2-amine (205 mg, $1.14 \mathrm{mmol}), 3 q$ (143 mg, 39\%) was obtained as light yellow powder. ${ }^{1} \mathrm{H}-\mathrm{NMR}$ (DMSO- $\left.d_{6}\right) \delta: 3.82(3 \mathrm{H}, \mathrm{s}), 7.06$ $(1 \mathrm{H}, \mathrm{dd}, J=8.8,2.4 \mathrm{~Hz}), 7.42(1 \mathrm{H}, \mathrm{d}, J=4.0 \mathrm{~Hz}), 7.60(1 \mathrm{H}, \mathrm{d}$, $J=2.4 \mathrm{~Hz}), 7.64(1 \mathrm{H}, \mathrm{d}, J=8.8 \mathrm{~Hz}), 8.06(1 \mathrm{H}, \mathrm{s}) .{ }^{13} \mathrm{C}-\mathrm{NMR}$ $\left(\mathrm{DMSO}-d_{6}\right) \delta: 55.6,104.9,115.1,119.8,120.4,120.7,131.9$, $132.2,132.4,139.4,156.3,156.7,160.9$. HPLC purity: $>99 \%$, ESI-MS $m / z 369[\mathrm{M}+\mathrm{H}]^{+}$.

5-Bromo- $N$-(4-methoxybenzo $[d]$ thiazol-2-yl)thiophene2-carboxamide (3r) According to the same procedure used for 3a, starting from 5-bromothiophene-2-carboxylic acid $(207 \mathrm{mg}, 1.00 \mathrm{mmol})$ and 4-methoxylbenzo $[d]$ thiazol-2-amine (198 mg, $1.10 \mathrm{mmol}), 3 \mathbf{r}(170 \mathrm{mg}, 46 \%)$ was obtained as white powder. ${ }^{1} \mathrm{H}-\mathrm{NMR}\left(\mathrm{DMSO}-d_{6}\right) \delta: 3.93(3 \mathrm{H}, \mathrm{s}), 7.02(1 \mathrm{H}, \mathrm{d}$, $J=8.0 \mathrm{~Hz}), 7.29(1 \mathrm{H}, \mathrm{t}, J=8.0 \mathrm{~Hz}), 7.43(1 \mathrm{H}, \mathrm{d}, J=4.0 \mathrm{~Hz}), 7.55$ $(1 \mathrm{H}, \mathrm{d}, J=8.0 \mathrm{~Hz}), 8.12(1 \mathrm{H}, \mathrm{s}) \cdot{ }^{13} \mathrm{C}-\mathrm{NMR}\left(\mathrm{DMSO}-d_{6}\right) \delta: 55.7$, $107.6,113.4,120.1,124.8,132.0,132.3,132.9,138.4,138.8$, 151.9, 156.6, 159.1. HPLC purity: >99\%, ESI-MS $\mathrm{m} / \mathrm{z} 369$ $[\mathrm{M}+\mathrm{H}]^{+}$.

5-Bromo- $N$-(6-ethoxybenzo $[d]$ thiazol-2-yl)thiophene2-carboxamide (3s) According to the same procedure used for $\mathbf{2 b}$, starting from 5-bromothiophene-2-carboxylic acid $(207 \mathrm{mg}, 1.00 \mathrm{mmol})$ and 6-ethoxylbenzo $[d]$ thiazol-2-amine (214 mg, $1.10 \mathrm{mmol}), 3 \mathrm{~s}$ (163 mg, 43\%) was obtained as white powder. ${ }^{1} \mathrm{H}-\mathrm{NMR}\left(\mathrm{DMSO}-d_{6}\right) \delta: 1.36(3 \mathrm{H}, \mathrm{t}, J=2.8 \mathrm{~Hz}), 4.08$ $(2 \mathrm{H}, \mathrm{q}, J=2.8 \mathrm{~Hz}), 7.05(1 \mathrm{H}, \mathrm{ddd}, J=8.4,2.4,0.8 \mathrm{~Hz}), 7.42(1 \mathrm{H}$, d, $J=4.0 \mathrm{~Hz}), 7.58(1 \mathrm{H}, \mathrm{d}, J=2.4 \mathrm{~Hz}), 7.63(1 \mathrm{H}, \mathrm{d}, J=8.4 \mathrm{~Hz})$, $8.06(1 \mathrm{H}, \mathrm{s}) .{ }^{13} \mathrm{C}-\mathrm{NMR}$ (DMSO- $\left.d_{6}\right) \delta: 14.7,63.6,105.5,115.5$, $119.8,120.6,131.9,132.2,132.5,139.4,142.4,155.5,156.7$, 159.5. HPLC purity: $>99 \%$, ESI-MS $m / z 383[\mathrm{M}+\mathrm{H}]^{+}$.

5-Bromo- $N$-(6-nitrobenzo $[d]$ thiazol-2-yl)thiophene2-carboxamide (3t) According to the same procedure used for 2d, starting from 5-bromothiophene-2-carboxylic acid $(207 \mathrm{mg}, \quad 1.00 \mathrm{mmol})$ and 6-nitrobenzo $[d]$ thiazol-2-amine (215 mg, $1.10 \mathrm{mmol}), 3 \mathrm{t}(339 \mathrm{mg}, 88 \%$ ) was obtained as yellow powder. ${ }^{1} \mathrm{H}-\mathrm{NMR}\left(\mathrm{DMSO}-d_{6}\right) \delta: 7.40(1 \mathrm{H}, \mathrm{d}, J=4.0 \mathrm{~Hz}), 7.88$ $(1 \mathrm{H}, \mathrm{d}, J=8.8 \mathrm{~Hz}), 8.09(1 \mathrm{H}, \mathrm{d}, J=4.0 \mathrm{~Hz}), 8.28(1 \mathrm{H}, \mathrm{dd}, J=8.8$, $2.4 \mathrm{~Hz}), 8.99(1 \mathrm{H}, \mathrm{d}, J=2.4 \mathrm{~Hz}) .{ }^{13} \mathrm{C}-\mathrm{NMR}\left(\mathrm{DMSO}-d_{6}\right) \delta: 118.6$, $119.6,120.2,121.5,131.7,131.9,132.5,138.3,143.0,152.1$, 160.1, 164.0. HPLC purity: 96\%, ESI-MS m/z $382[\mathrm{M}-\mathrm{H}]^{-}$. 
5-Bromo- $N$-(6-(trifluoromethyl)benzo $[d]$ thiazol-2-yl)thiophene-2-carboxamide (3u) A mixture of 5-bromothiophene2-carboxylic acid (208 mg, $1.00 \mathrm{mmol}), 6$-(trifluoromethyl)benzo[d]thiazol-2-amine (241 mg, $1.10 \mathrm{mmol})$, DMAP (184 mg, $1.50 \mathrm{mmol})$ and $\mathrm{EDC} \cdot \mathrm{HCl}(288 \mathrm{mg}, 1.50 \mathrm{mmol})$ in $\mathrm{CH}_{2} \mathrm{Cl}_{2}$ ( $2 \mathrm{~mL}$ ) was stirred overnight at $\mathrm{rt} . \mathrm{CH}_{2} \mathrm{Cl}_{2}$ and $2 \mathrm{~N} \mathrm{HCl}$ were added, the precipitate was washed several times with $\mathrm{CH}_{2} \mathrm{Cl}_{2}$ and $\mathrm{MeOH}$. The residue was purified by preparative layer chromatography (eluent: $\mathrm{CHCl}_{3} / \mathrm{MeOH}=30: 1$ ) to give $\mathbf{3 u}$ $(184 \mathrm{mg}, 70 \%)$ as white powder. ${ }^{1} \mathrm{H}-\mathrm{NMR}\left(\mathrm{DMSO}-d_{6}\right) \delta: 7.44$ $(1 \mathrm{H}, \mathrm{d}, J=4.0 \mathrm{~Hz}), 7.77(1 \mathrm{H}, \mathrm{dd}, J=8.0,1.6 \mathrm{~Hz}), 7.92(1 \mathrm{H}, \mathrm{d}$, $J=8.0 \mathrm{~Hz}), 8.12(1 \mathrm{H}, \mathrm{s}), 8.51(1 \mathrm{H}, \mathrm{s}) .{ }^{13} \mathrm{C}-\mathrm{NMR}$ (DMSO- $\left.d_{6}\right) \delta$ : $120.3(\mathrm{~d}, J=4.1 \mathrm{~Hz}), 120.4,120.6,123.2$ (d, $J=4.1 \mathrm{~Hz}), 123.9$ (q, $J=32.2 \mathrm{~Hz}), 125.9,128.6,131.9,132.4,132.5,132.7,138.7$, 165.2. HPLC purity: $>99 \%$, ESI-MS $m / z 407[\mathrm{M}+\mathrm{H}]^{+}$.

5-Bromo- $N$-(6-(trifluoromethoxy)benzo $[d]$ thiazol-2yl)thiophene-2-carboxamide (3v) According to the same procedure used for $\mathbf{2 a}$, starting from 5-bromothiophene-2-carboxylic acid $(207 \mathrm{mg}, 1.00 \mathrm{mmol})$ and 6-(trifluoromethoxyl)benzo[ $d]$ thiazol-2-amine $(258 \mathrm{mg}, 1.10 \mathrm{mmol}), \quad 3 \mathbf{v} \quad(22 \mathrm{mg}$, $5 \%$ ) was obtained as white powder. ${ }^{1} \mathrm{H}-\mathrm{NMR}$ (DMSO- $\left.d_{6}\right)$ $\delta$ : $7.43-7.47(2 \mathrm{H}, \mathrm{m}), 7.84(1 \mathrm{H}, \mathrm{dt}, J=8.8 \mathrm{~Hz}), 8.11(1 \mathrm{H}, \mathrm{d}$, $J=3.2 \mathrm{~Hz}), 8.15(1 \mathrm{H}, \mathrm{d}, J=2.4 \mathrm{~Hz}) .{ }^{13} \mathrm{C}-\mathrm{NMR}\left(\mathrm{DMSO}-d_{6}\right) \delta$ : $115.1,120.0,120.2$ (q, $J=256.2 \mathrm{~Hz}), 120.3,121.1,132.3,132.4$, $132.5(\mathrm{~d}, J=5.7 \mathrm{~Hz}), 138.8(\mathrm{~d}, J=6.6 \mathrm{~Hz}), 144.2,144.9,160.0$, 160.3. HPLC purity: $>99 \%$, ESI-MS $m / z 423[\mathrm{M}+\mathrm{H}]^{+}$.

Ethyl 2-(5-Bromothiophene-2-carboxamido)benzo[d]thiazole-6-carboxylate $(3 \mathbf{w})$ According to the same procedure used for $\mathbf{2 a}$, starting from 5-bromothiophene-2-carboxylic acid $(207 \mathrm{mg}, 1.00 \mathrm{mmol})$ and ethyl 2-aminobenzo $[d]$ thiazole-6carboxylate $(244 \mathrm{mg}, 1.10 \mathrm{mmol}), 3 \mathbf{w}(184 \mathrm{mg}, 45 \%)$ was obtained as white powder. ${ }^{1} \mathrm{H}-\mathrm{NMR}\left(\mathrm{DMSO}-d_{6}\right) \delta$ : $1.36(3 \mathrm{H}, \mathrm{t}$, $J=3.2 \mathrm{~Hz}), 4.35(2 \mathrm{H}, \mathrm{q}, J=3.2 \mathrm{~Hz}), 7.43(1 \mathrm{H}, \mathrm{d}, J=4.0 \mathrm{~Hz}), 7.82$ $(1 \mathrm{H}, \mathrm{d}, J=8.0 \mathrm{~Hz}), 8.03(1 \mathrm{H}, \mathrm{dd}, J=8.0,1.6 \mathrm{~Hz}), 8.10(1 \mathrm{H}, \mathrm{s})$, $8.65(1 \mathrm{H}, \mathrm{s}) .{ }^{13} \mathrm{C}-\mathrm{NMR}$ (DMSO- $\left.d_{6}\right) \delta: 14.2,60.7,119.7,120.4$, $120.5,123.9,125.0,127.2,131.3,132.3,132.4,138.7,138.8$, 159.8, 165.4. HPLC purity: $>99 \%$, ESI-MS $m / z 411[\mathrm{M}+\mathrm{H}]^{+}$.

5-Bromo- $N$-(6-(tert-butyl)benzo $[d]$ thiazol-2-yl)thiophene2-carboxamide (3x) According to the same procedure used for $3 \mathbf{u}$ (eluent : $\mathrm{CHCl}_{3} / \mathrm{MeOH}=40: 1$ ), starting from 5-bromothiophene-2-carboxylic acid $(207 \mathrm{mg}, 1.00 \mathrm{mmol})$ and 6-(tert-butyl)benzo[d]thiazol-2-amine $(227 \mathrm{mg}, 1.10 \mathrm{mmol}), 3 \mathbf{x}$ (225 mg, 57\%) was obtained as light yellow powder. ${ }^{1} \mathrm{H}-\mathrm{NMR}$ $\left(\mathrm{DMSO}-d_{6}\right) \delta: 1.35(9 \mathrm{H}, \mathrm{s}), 7.42(1 \mathrm{H}, \mathrm{d}, J=3.6 \mathrm{~Hz}), 7.52(1 \mathrm{H}$, $\mathrm{d}, J=8.8 \mathrm{~Hz}), 7.64(1 \mathrm{H}, \mathrm{s}), 8.00(1 \mathrm{H}, \mathrm{s}), 8.05(1 \mathrm{H}, \mathrm{s}) .{ }^{13} \mathrm{C}-\mathrm{NMR}$ $\left(\mathrm{DMSO}-d_{6}\right) \delta: 31.4,34.7,118.0,119.1,119.8,124.1,131.0,131.9$, 132.2, 139.5, 146.7, 147.0, 159.7, 160.4. HPLC purity: 97\%, ESI-MS $m / z 395[\mathrm{M}+\mathrm{H}]^{+}$.

5-Chloro- $N$-(4,6-difluorobenzo[ $d]$ thiazol-2-yl)thiophene2-carboxamide (4a) According to the same procedure used for $\mathbf{2 f}$, starting from 5-chlorothiophene-2-carboxylic acid $(163 \mathrm{mg}, 1.00 \mathrm{mmol})$ and 4,6-difluorobenzo[d]thiazol-2-amine (205 mg, $1.10 \mathrm{mmol}), 4 a(192 \mathrm{mg}, 58 \%)$ was obtained as white powder. mp: $247-249^{\circ} \mathrm{C} .{ }^{1} \mathrm{H}-\mathrm{NMR}\left(\mathrm{DMSO}-d_{6}\right) \delta$ : $7.35(1 \mathrm{H}, \mathrm{d}$, $J=4.0 \mathrm{~Hz}), 7.40(1 \mathrm{H}, \mathrm{dt}, J=10.2,2.4 \mathrm{~Hz}), 7.83(1 \mathrm{H}, \mathrm{dd}, J=8.4$, $2.4 \mathrm{~Hz}), 8.21(1 \mathrm{H}, \mathrm{d}, J=4.0 \mathrm{~Hz}) .{ }^{13} \mathrm{C}-\mathrm{NMR}\left(\mathrm{DMSO}-d_{6}\right) \delta: 102.4$ (dd, $J=28.9,22.3 \mathrm{~Hz}), 104.5$ (dd, $J=26.4,4.1 \mathrm{~Hz}), 129.0,131.8$, 133.8, 133.9 (dd, $J=13.3,4.1 \mathrm{~Hz}), 134.9$ (dd, $J=13.3,4.1 \mathrm{~Hz})$, 135.5, 136.5, 153.3 (d, $J=250.4,15.4 \mathrm{~Hz}), 158.2$ (dd, $J=242.2$, $9.8 \mathrm{~Hz}), 158.6$. HPLC purity: $>99 \%$, ESI-MS $m / z 331[\mathrm{M}+\mathrm{H}]^{+}$.

3,5-Dibromo- $N$-(4,6-difluorobenzo $[d]$ thiazol-2-yl)thio- phene-2-carboxamide (4b) According to the same procedure used for $\mathbf{2 f}$, starting from 3,5-dibromothiophene-2-carboxylic acid $(286 \mathrm{mg}, 1.00 \mathrm{mmol})$ and 4,6-difluorobenzo[d]thiazol-2-amine (204 mg, $1.10 \mathrm{mmol}), \quad 4 b \quad(270 \mathrm{mg}, \quad 60 \%)$ was obtained as white powder. mp: $245-246^{\circ} \mathrm{C} .{ }^{1} \mathrm{H}-\mathrm{NMR}$ $\left(\mathrm{DMSO}-d_{6}\right) \delta: 7.43(1 \mathrm{H}, \mathrm{dt}, J=10.2,2.0 \mathrm{~Hz}), 7.56(1 \mathrm{H}, \mathrm{s}), 7.83$ $(1 \mathrm{H}, \mathrm{dd}, J=8.4,2.0 \mathrm{~Hz}) .{ }^{13} \mathrm{C}-\mathrm{NMR}\left(\mathrm{DMSO}-d_{6}\right) \delta: 102.2$ (dd, $J=28.0,23.1 \mathrm{~Hz}), 104.7(\mathrm{dd}, J=26.4,3.3 \mathrm{~Hz}), 114.3,118.4,131.4$ (d, $J=7.4 \mathrm{~Hz}), 134.3$ (d, $J=10.7 \mathrm{~Hz}), 134.9,135.2,152.7$ (d, $J=241.2,20.7 \mathrm{~Hz}), 158.3$ (dd, $J=242.2,10.7 \mathrm{~Hz}), 159.0,159.7$. HPLC purity: $>99 \%$, ESI-MS $m / z 453[\mathrm{M}+\mathrm{H}]^{+}$.

3,5-Dichloro- $N$-(4,6-difluorobenzo $[d]$ thiazol-2-yl)thiophene-2-carboxamide (4c) According to the same procedure used for 3a (eluent : $\mathrm{CHCl}_{3} / \mathrm{MeOH}=20: 1$ to $4: 1$ ), starting from 3,5-dichlorothiophene-2-carboxylic acid $(197 \mathrm{mg}$, $1.00 \mathrm{mmol})$ and 4,6-difluorobenzo[ $d]$ thiazol-2-amine $(205 \mathrm{mg}$, $1.10 \mathrm{mmol}), 4 \mathrm{c}(165 \mathrm{mg}, 45 \%)$ was obtained as white powder. mp: $224-225^{\circ} \mathrm{C} .{ }^{1} \mathrm{H}-\mathrm{NMR}\left(\mathrm{DMSO}-d_{6}\right) \delta: 7.29(1 \mathrm{H}, \mathrm{dt}, J=10.2$, $2.4 \mathrm{~Hz}), 7.75(1 \mathrm{H}, \mathrm{ddd}, J=8.8,2.4,1.2 \mathrm{~Hz}), 8.26(1 \mathrm{H}, \mathrm{s})$. ${ }^{13} \mathrm{C}-\mathrm{NMR}$ (DMSO- $d_{6}$ ) $\delta$ : $101.5(\mathrm{dd}, J=28.1,21.5 \mathrm{~Hz}), 103.9$ (dd, $J=26.4,4.9 \mathrm{~Hz}), 123.8,130.4,130.8,133.5$ (dd, $J=12.4,4.2 \mathrm{~Hz}$ ), 133.7, 134.7 (dd, $J=12.4,4.2 \mathrm{~Hz}$ ), 153.0 (dd, $J=254.6,14.1 \mathrm{~Hz}$ ), 158.0 (dd, $J=243.0,10.7 \mathrm{~Hz}), 158.3,158.6$. HPLC purity: 96\%, ESI-MS $m / z 365[\mathrm{M}+\mathrm{H}]^{+}$.

4,5-Dichloro- $N$-(4,6-difluorobenzo $[d]$ thiazol-2-yl)thiophene-2-carboxamide (4d) According to the same procedure used for $\mathbf{2 d}$, starting from 4,5-dichlorothiophene-2-carboxylic acid $(198 \mathrm{mg}, 1.00 \mathrm{mmol})$ and 4,6-difluorobenzo[d]thiazol-2-amine (205 mg, $1.10 \mathrm{mmol}), \mathbf{4 d}(268 \mathrm{mg}, 73 \%)$ was obtained as white powder. mp: $225-226^{\circ} \mathrm{C} .{ }^{1} \mathrm{H}-\mathrm{NMR}$ (DMSO$\left.d_{6}\right) \delta: 7.29(1 \mathrm{H}, \mathrm{t}, J=10.2 \mathrm{~Hz}), 7.75(1 \mathrm{H}, \mathrm{d}, J=8.0 \mathrm{~Hz}), 8.26(1 \mathrm{H}$, s). ${ }^{13} \mathrm{C}-\mathrm{NMR}\left(\mathrm{DMSO}-d_{6}\right) \delta$ : $101.6(\mathrm{dd}, J=28.9,22.3 \mathrm{~Hz}), 104.0$ (dd, $J=26.5,4.9 \mathrm{~Hz}), 123.8,130.4,130.9,133.4$ (dd, $J=13.3$, $4.9 \mathrm{~Hz}), 133.6,134.7$ (dd, $J=13.3,4.9 \mathrm{~Hz}), 153.1$ (dd, $J=253.7$, $13.3 \mathrm{~Hz}), 158.0(\mathrm{dd}, J=243.0,10.7 \mathrm{~Hz}), 158.3,158.6$. HPLC purity: $>99 \%$, ESI-MS $m / z 365[\mathrm{M}+\mathrm{H}]^{+}$.

\section{Biological Assay}

Material

Stock solutions (10 and $100 \mathrm{~mm}$ ) of each compound were prepared in DMSO and kept at $-20^{\circ} \mathrm{C}$. Appropriate dilutions were freshly prepared just prior to each assay. MNV (S7 strain, kindly provided by Prof. Yukinobu Tohya, Department of Veterinary Medicine, Nihon University, Kanagawa, Japan) was propagated in RAW 264.7 cells (ATC C TIB-71; American Type Culture Collection, Manassas, VA, U.S.A.) cultured in Dulbecco's modified Eagle's medium (DMEM) supplemented with $10 \%$ (growth medium) or $2 \%$ (maintenance medium) heat-inactivated fetal bovine serum, antibiotics $(100 \mathrm{U} / \mathrm{mL}$ penicillin, $100 \mu \mathrm{g} / \mathrm{mL}$ streptomycin, and $0.25 \mu \mathrm{g} / \mathrm{mL}$ amphotericin B), $4500 \mathrm{mg} / \mathrm{L}$ D-glucose, $4 \mathrm{~mm}$ L-glutamine, $25 \mathrm{~mm} \mathrm{~N}$ (2-hydroxyethyl)piperazine- $N^{\prime}$-2-ethanesulfonic acid (HEPES), $1 \mathrm{~mm}$ sodium pyruvate, and $15 \mathrm{mg} / \mathrm{L}$ phenol red at $37^{\circ} \mathrm{C}$ in a humidified atmosphere of $5 \% \mathrm{CO}_{2}$. The virus was titrated in RAW264.7 cells with a conventional assay as described previously. ${ }^{16)}$ After infection for $3 \mathrm{~d}$, the cells were observed for $\mathrm{CPE}$, and the $\mathrm{TCID}_{50}$ was calculated by the Kärber formula. Cell debris was removed by centrifugation at $10000 \times \boldsymbol{g}$ for $1 \mathrm{~h}$, and the supernatant was stored at $-80^{\circ} \mathrm{C}$ until use. RAW264.7 cells $\left(5.0 \times 10^{3}\right.$ cells/well) were seeded in a 96 -well plate in growth medium. After incubation for $24 \mathrm{~h}$, cells were used for antiviral or cytotoxicity assay. 


\section{Measurement of Anti-norovirus Activity}

Method A: Screening and CPE Reduction Assay

The antiviral activity of the compounds was determined by using a water-soluble tetrazolium salt (WST)-8 CPE reduction assay. $120 \mu \mathrm{L}$ of the mixture containing $280 \mathrm{TCID}_{50}$ of $\mathrm{MNV}$ and a dilution series of compounds $(0.0061-100 \mu \mathrm{M})$ with fetal bovine serum-free medium was incubated for $30 \mathrm{~min}$. RAW264.7 cells were exposed to the mixture. After incubation for $1 \mathrm{~h}$, the cells were washed, replaced with the maintenance medium and incubated for $3 \mathrm{~d}$ (i.e., until complete CPE was observed in infected untreated cells). To quantify cell viability, WST-8 solution was added and the plates were incubated for $1 \mathrm{~h}$. The absorbance was measured at $450 \mathrm{~nm}$. The $\mathrm{EC}_{50}$ was defined as the compound concentration that protected $50 \%$ of the cells from virus-induced CPE.

Antiviral activity of $\mathbf{4 b}$ was evaluated further at different time points. After infection with MNV for $1 \mathrm{~h}$, RAW264.7 cells were treated with a dilution series of $\mathbf{4 b}, 2^{\prime}-\mathrm{CMC}$, and GC376 for $72 \mathrm{~h}$.

The methods for screening and measuring the antiviral activity of the compounds were similar. However, for screening, $100 \mathrm{TCID}_{50} / 50 \mu \mathrm{L}$ of $\mathrm{MNV}$ and $25 \mu \mathrm{M}$ of the compounds were used and CPE was observed by microscope without measuring the absorbance.

Method B: TCID $_{50}$ Assay with Filtration

A total volume of $50 \mu \mathrm{L}$ of the mixture containing $225 \mu \mathrm{M}$ compound (4b, 2'-CMC, and GC376) in fetal bovine serum-free medium and $3150 \mathrm{TCID}_{50}$ of MNV was incubated at room temperature in a centrifugal filter tube (Amicon Ultra-0.5 (100K), Merck Millipore). In an experiment of $0.02 \%(\mathrm{v} / \mathrm{v})$ sodium hypochlorite, commercial breach in distilled water was used instead of compound solution. After $1 \mathrm{~h}, 450 \mu \mathrm{L}$ of fetal bovine serum-free medium was added and spun at $20000 \times \boldsymbol{g}$ for $1 \mathrm{~min}$ to eliminate compound. The wash step was repeated once more. MNV was recovered from the filter according to the manufacturer's instructions and was 5-fold serially diluted with fetal bovine serum-free medium. RAW264.7 cells in a 96-well plate were infected with the diluted virus solution. After $3 \mathrm{~d}$, the cells were observed for CPE, and TCID $_{50}$ was calculated.

Cytotoxicity Assay The cytotoxicity of compounds was evaluated by the WST- 8 assay in triplicate. RAW264.7 cells were exposed to $3-100 \mu \mathrm{M}$ of each compound for $72 \mathrm{~h}$. Control cells were treated with the maximum concentration of DMSO $(0.1 \%)$ and the same incubation time. Cell viability was evaluated by the WST- 8 method described in the previous section. $\mathrm{CC}_{50}$ was defined as the compound concentration that reduces the number of viable cells by $50 \%$.
Acknowledgments We acknowledge Prof. Yukinobu Tohya (Department of Veterinary Medicine, Nihon University, Kanagawa, Japan) for providing MNV (virus strain S-7). We thank Ms. Nao Miyoshi for excellent technical assistance in the cytotoxicity assay.

Conflict of Interest The authors declare no conflict of interest.

\section{References}

1) Robilotti E., Deresinski S., Pinsky B. A., Clin. Microbiol. Rev., 28 , 134-164 (2015).

2) Jones M. K., Watanabe M., Zhu S., Graves C. L., Keyes L. R., Grau K. R., Gonzalez-Hernandez M. B., Iovine N. M., Wobus C. E., Vinjé J., Tibbetts S. A., Wallet S. M., Karst S. M., Science, 346, 755-759 (2014).

3) Jones M. K., Grau K. R., Costantini V., Kolawole A. O., de Graaf M., Freiden P., Graves C. L., Koopmans M., Wallet S. M., Tibbetts S. A., Schultz-Cherry S., Wobus C. E., Vinjé J., Karst S. M., Nat. Protoc., 10, 1939-1947 (2015).

4) Wobus C. E., Karst S. M., Thackray L. B., Chang K.-O., Sosnovtsev S. V., Belliot G., Krug A., Mackenzie J. M., Green K. Y., Virgin H. W., PLoS Biol., 2, e432 (2004).

5) Wobus C. E., Thackray L. B., Virgin H. W. 4th, J. Virol., 80, 51045112 (2006).

6) Rocha-Pereira J., Cunha R., Pinto D. C., Silva A. M., Nascimento M. S. J., Bioorg. Med. Chem., 18, 4195-4201 (2010).

7) Arias A., Emmott E., Vashist S., Goodfellow I., Future Microbiol., 8, 1475-1487 (2013).

8) Kim Y., Galasiti Kankanamalage A. C., Chang K.-O., Groutas W. C., J. Med. Chem., 58, 9438-9450 (2015).

9) Rocha-Pereira J., Jochmans D., Dallmeier K., Leyssen P., Cunha R., Costa I., Nascimento M. S. J., Neyts J., Biochem. Biophys. Res. Commun., 427, 796-800 (2012).

10) Rocha-Pereira J., Jochmans D., Debing Y., Verbeken E., Nascimento M. S. J., Neyts J., J. Virol., 87, 11798-11805 (2013).

11) Rocha-Pereira J., Jochmans D., Dallmeier K., Leyssen P., Nascimento M. S. J., Neyts J., Biochem. Biophys. Res. Commun., 424, 777-780 (2012).

12) Takahashi D., Kim Y., Lovell S., Prakash O., Groutas W. C., Chang K.-O., Virus Res., 178, 437-444 (2013).

13) Kitajima M., Tohya Y., Matsubara K., Haramoto E., Utagawa E., Katayama H., Lett. Appl. Microbiol., 51, 119-121 (2010).

14) Oka T., Yokoyama M., Katayama K., Tsunemitsu H., Yamamoto M., Miyashita K., Ogawa S., Motomura K., Mori H., Nakamura H., Wakita T., Takeda N., Sato H., Virology, 394, 119-129 (2009).

15) Kim Y., Lovell S., Tiew K.-C., Mandadapu S. R., Alliston K. R., Battaile K., Groutas W. C., Chang K.-O., J. Virol., 86, 11754-11762 (2012).

16) Kitajima M., Oka T., Takagi H., Tohya Y., Katayama H., Takeda N., Katayama K., J. Virol. Methods, 169, 269-273 (2010). 